\title{
Genetic and Systematic Approaches Toward G Protein-Coupled Abiotic Stress Signaling in Plants
}

\author{
Ting-Ying $\mathrm{Wu}^{1 *}$ and Daisuke Urano ${ }^{1,2 *}$ \\ ${ }^{1}$ Temasek Life Sciences Laboratory, Singapore, Singapore, ${ }^{2}$ Department of Biological Sciences, National University of \\ Singapore, Singapore, Singapore
}

OPEN ACCESS

Edited by:

Eric Ruelland,

Centre National de la Recherche

Scientifique (CNRS), France

Reviewed by:

Yunqing $Y u$,

Donald Danforth Plant Science Center,

United States

Sylvie Coursol,

Institut National de la Recherche

Agronomique (INRA), France

*Correspondence:

Ting-Ying Wu

tingying@tll.org.ss

Daisuke Urano

daisuke@tll.org.sg

Specialty section:

This article was submitted to

Plant Abiotic Stress,

a section of the journal

Frontiers in Plant Science

Received: 11 May 2018

Accepted: 29 August 2018

Published: 20 September 2018

Citation:

Wu T-Y and Urano D (2018) Genetic and Systematic Approaches Toward

G Protein-Coupled Abiotic Stress Signaling in Plants.

Front. Plant Sci. 9:1378. doi: 10.3389/fpls.2018.01378
Heterotrimeric $G$ protein, composed of $G \alpha, G \beta$, and $G \gamma$ subunits, modulates plant adaptations to environmental stresses such as high salinity, drought, extreme temperatures and high light intensity. Most of these evidence were however derived solely from conventional genetics methods with which stress-associated phenotypes were compared between wild type and various $\mathrm{G}$ protein mutant plants. Recent advances in systematic approaches, mainly transcriptome and proteome, have contributed to in-depth understanding of molecular linkages between $G$ proteins and environmental changes. Here, we update our knowledge on the roles of $\mathrm{G}$ proteins in abiotic stress responses. Furthermore, we highlight the current whole genome studies and integrated omics approach to better understand the fundamental $G$ protein functions involved in abiotic stress responses. It is our purpose here to bridge the gap between molecular mechanisms in $\mathrm{G}$ protein science and stress biology and pave the way toward crop improvement researches in the future.

Keywords: systems biology, bioinformatics, G proteins, environmental stress, omics

\section{INTRODUCTION TO G PROTEINS}

Plants experience frequent changes in their growth environments which impede or alter their normal development. Environmental conditions include biotic stresses such as pathogen infection and abiotic stresses such as drought, high salinity, heat, cold, excessive light, high ultraviolet B (UVB) radiation, nutrient deficiency and accumulation of toxic metals in the soil. Due to the increased frequency of extreme weather and climate change in recent years, the adverse effects from those abiotic stresses have been accelerated in plants ( $\mathrm{hhu}, 2016$ ). As a sessile organism, plants have developed many mechanisms to cope with unfavorable environments. How plants use the complicated combination of transcriptional and/or translational reprogramming to gain stress tolerance are pivotal biological questions. In this review, we will discuss the role of $\mathrm{G}$ protein genes in abiotic stress responses from the aspect of morphological adaptations to molecular mechanisms. We then further highlight the potential strategies to systematically integrate $G$ protein science and stress biology.

Heterotrimeric $\mathrm{G}$ protein, composed of $\mathrm{G} \alpha, \mathrm{G} \beta$, and $\mathrm{G} \gamma$ subunits, is a well-conserved signaling protein that functions as a molecular switch in eukaryotes. In the steady state, $\mathrm{G} \alpha$ subunit holds a guanosine diphosphate (GDP) and forms an inactive complex with an obligate G $\beta \gamma$ dimer. Upon nucleotide exchange on $\mathrm{G} \alpha$ for a guanosine triphosphate (GTP), GTP-bound $\mathrm{G} \alpha$ dissociates from G $\beta \gamma$ then modulates the activity of downstream signaling proteins (Kaziro et al., 1991). While seven-transmembrane (7TM) G protein-coupled receptors (GPCRs) predominantly modulate the activity of heterotrimeric $G$ protein in animals, single-transmembrane receptor kinases are 
the primary regulators of plant heterotrimeric $G$ protein rather than hypothetical GPCR candidates with 7TM helices, such as G protein Coupled Receptor 1 (GCR1) (Aranda-Sicilia et al., 2015; Liang et al., 2016; Tunc-Ozdemir et al., 2016; Yu et al., 2018). In contrast to the receptor kinases, Regulator of $G$ protein Signaling (RGS) negatively modulates the activity of $G$ protein on the plasma membrane (Chen et al., 2003; Urano et al., 2015; Hackenberg et al., 2017; Figure 1A). Typical seed plants have two types of $\mathrm{G} \alpha$; a canonical $\mathrm{G} \alpha$ and a non-canonical extra-large $\mathrm{G} \alpha$ (XLG), a single type of G $\beta$ and three types of $G \gamma$; Type-A, -B and - C G $\gamma$ subunits (Figure 1B).

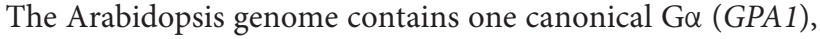
three XLG (XLG1, XLG2 and XLG3), one Gß (AGB1) and three
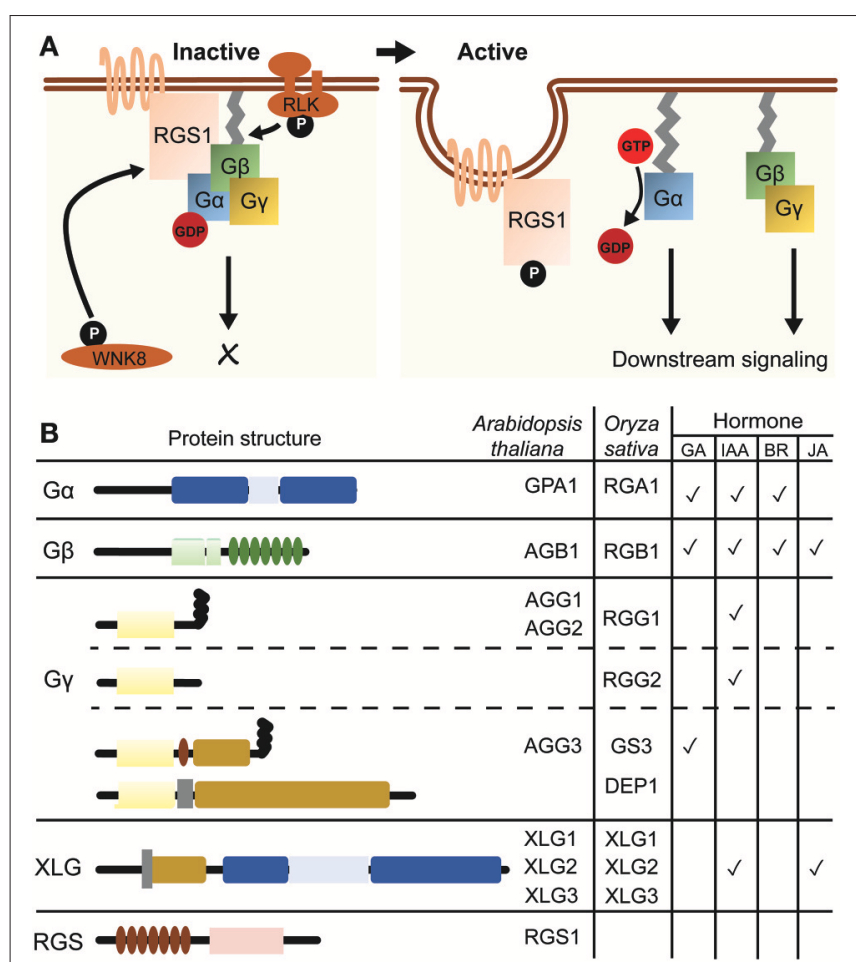

FIGURE 1 | A model of G protein signaling pathway and their structural characteristics. (A) A model for G protein cycle in Arabidopsis. AtRGS1 keeps the $\mathrm{G} \alpha \beta \gamma$ complex in the inactive state by augmenting the hydrolysis of GTP to GDP. AtGRS1 is phosphorylated at the $\mathrm{C}$ terminus by membrane-associated or cytosolic kinases such as WNK8 and receptor-like kinases (RLK), and then undergoes endocytosis. Upon uncoupling from AtRGS1, $\mathrm{G} \alpha$ subunit is able to exchange GDP for GTP and is detached from G $\beta \gamma$ dimer, then activates the downstream effectors. (B) Domain architectures of Arabidopsis and rice $G$ protein subunits and AtRGS1. AtGPA1 contains a Ras-like domain and a helical domain. AGB1 contains a coiled-coil domain in the $\mathrm{N}$-terminal region and seven WD40 repeats. G $\gamma$ subunit can be classified into type A, B and C subgroups. Type $A$ is composed of a $G \gamma$-domain and a CaaX motif, while type $B$ is composed of only a $G \gamma$-domain. Type $C$ contains a $G \gamma$-domain, a cysteine-rich domain, a NLS, a CaaX motif and a transmembrane domain. Arabidopsis has no type B Gy subunit. XLGs are composed of a NLS, a cysteine-rich domain, a Ras-like domain and a helical domain. AtRGS1 contains a 7-TM domain and a RGS domain. Rice has no RGS homolog. The table on the right summarizes $\mathrm{G}$ protein subunits related to hormone regulations, as discussed in the main text.
Gy (AGG1, AGG2, and AGG3) genes. Genetic ablation of some G protein genes confers various anomalous morphologies including leaf and flower shape, hypocotyl elongation and root mass and architecture. G protein mutations also alter the sensitivity to growth hormones including auxin, gibberellic acid (GA) and brassinosteroid (BR). In general, $\mathrm{G} \alpha$ mutants are hyposensitive to auxin, GA and $B R$, while $G \beta$ mutants are hypersensitive to auxin but hyposensitive to GA and BR (Ueguchi-Tanaka et al., 2000; Ullah et al., 2001, 2003; Wang et al., 2006; Gao et al., 2008; Oki et al., 2009; Chakravorty et al., 2011). Some of these developmental phenotypes and hormonal responses are comparable in $\mathrm{G} \alpha, \mathrm{G} \beta$, or $\mathrm{G} \gamma$ null mutants while others are opposite between these mutant lines. The complete knockout of GPA1/XLG or three types of AGG mimics all known phenotypes conferred by the null mutation in AGB1 (Urano et al., 2016a) For further details of $\mathrm{G}$ protein functions in plant development and hormone perception, readers may refer to previous review articles (Assmann, 2004; Urano et al., 2013, 2016b; Pandey and Vijayakumar, 2018).

\section{G PROTEINS AND ABIOTIC STRESS RESPONSE IN PLANTS}

Besides regulating several developmental processes and phytohormone responses, plant $G$ proteins modulate a broad range of abiotic and biotic stress responses. Plants cope with abiotic stresses such as high salinity, drought, high light and extreme temperatures through the activation of dynamic signaling transductions in the cell. This section summarizes the relationship between $G$ protein pathways and a variety of environmental changes.

\section{Salt Stress}

High soil salinity causes osmotic and ionic toxicity in plants resulting in reduced plant growth and crop yield (Zhu, 2002). High osmolarity rapidly inhibits cell proliferation in shoot apical meristem hence slowing down plant growth while ionic toxicity causes necrosis in the leaf tips and margins. Arabidopsis $A G B 1$, triple $X L G$, and triple $A G G$ null mutants exhibit smaller and chlorotic leaves when grown on $\mathrm{NaCl}$-containing medium, whereas the seedlings and leaves of wild type plants remain greenish (Colaneri et al., 2014; Yu and Assmann, 2015; Liang et al., 2017). The hypersensitive phenotype of $a g b 1$ is likely due to ionic toxicity, since agbl shows a similar leafbleaching phenotype with different ionic treatments but not with a changing water content (Colaneri et al., 2014; Yu and Assmann, 2015). Arabidopsis agb1 mutant accumulates $\mathrm{Na}^{+}$ in both shoots and roots (Yu and Assmann, 2015, 2016), suggesting that AGB1 regulates $\mathrm{Na}^{+}$fluxes in roots and the translocation of $\mathrm{Na}^{+}$from roots to shoots (Yu and Assmann, 2015). Arabidopsis gpal and rgs 1 mutants contrastingly show larger and less chlorotic leaves under $\mathrm{NaCl}$ treatment (Colaneri et al., 2014). In accord with the phenotypes in Arabidopsis, $\mathrm{G} \alpha$-null mutation in rice and maize attenuated leaf senescence, chlorophyll degradation and cytoplasm electrolyte leakage caused by a high concentration of sodium chloride (Urano et al., 


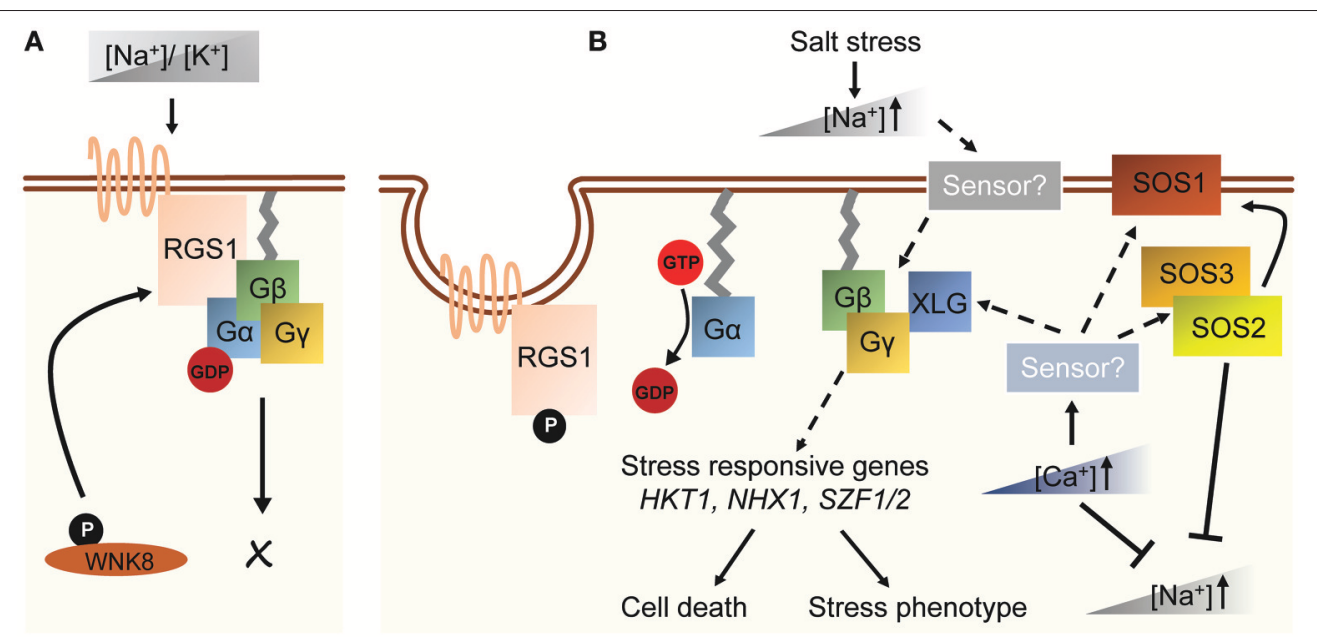

FIGURE 2 | A schematic model of G protein-related salt response in Arabidopsis. (A) In normal growth condition, the homeostasis of [Na $\left.{ }^{+}\right]$and $\left[\mathrm{K}^{+}\right]$is balanced. The G-protein complex is not activated. (B) Salt stress causes the elevation of cytosolic [ $\left.\mathrm{Na}^{+}\right]$concentration that is sensed by hypothetical sodium sensors on plasma membrane or in cytosol. Breakdown of ion homeostasis activates following signaling pathways. These include increasing of [Ca $\left.{ }^{2+}\right]$, activation of $S O S$ genes and induction of G $\beta \gamma$ - and XLG-regulated genes such as HKT1, SZF1/2 and NHX1. The subsequent signaling pathways then invoke stress responses and cell death in plants. Dashed arrows indicate indirect or hypothetical regulations, and solid arrows indicate direct regulations.

2014). Similarly, overexpression of $R G G 1$ in rice improved salt tolerance without affecting yield (Swain et al., 2017), suggesting a conserved stress-related role of heterotrimeric $\mathrm{G}$ protein across spermatophyte linages (Table 2). Several G protein interactors are genetically associated with G-proteins in the salt stress response. For example, a knockout mutant for With No Lysine 8 (WNK8) kinase, which phosphorylates RGS1 and induces its endocytosis, improved salt tolerance additively with $\operatorname{rgs} 1$ in Arabidopsis (Urano et al., 2012, 2014; Colaneri et al., 2014; Cao-Pham et al., 2018). Recently, SALT INDUCIBLE ZINC FINGER 1, and 2 (SZF1 and SZF2) were found to be involved in salt stress response in the XLG-dependent pathway (Liang et al., 2017) Several $\mathrm{Na}+$ transporters and sensors such as SOS, HKT1, and NHX1 showed contradicted expression level in agb1 mutants under salt stress (Figure 2; Ma et al., 2015a; Yu and Assmann, 2015). Therefore, the comprehensive molecular mechanism has not yet been deciphered (Table 1 and Figure 2).

\section{Drought Stress}

Drought decreases soil water content hence increases the concentrations of hydrogen and other ions in soil, which indirectly evokes multiple developmental and physiological changes similar to high salinity responses. Arabidopsis gpal and gcrl mutants displayed lower rates of water loss, which resulted in more resistant to drought stress. On the other hand, the agb1 mutants had a higher rate of water loss under drought treatment due to higher stomata density and hence it was intolerant to drought stress as compared to WT plants (Pandey and Assmann, 2004; Zhang et al., 2008; Nilson and Assmann, 2010b). Phenotypic plasticity is the ability of one genotype to modify phenotypes in response to different environments (Bradshaw, 1965; Huey, 2002). Given the fact that $G$ proteins regulate multiple signaling cross-talk in plants, they were therefore hypothesized to be plasticity genes, in which mutants might affect the degree of plasticity of a trait under environmental changes. Indeed, significant differences in developmental plasticity were observed between WT and G protein mutants for several reproduction-related traits under drought stress. For example, gpal or gcrl mutant showed increased plasticity for inflorescence height or fruit number respectively while agb1 mutants reduced plasticity for inflorescence height, seed number per fruit and total seed production in drought response (Nilson and Assmann, 2010a). Moreover, agb1 mutants showed increased total seed production under moderate and severe drought stress condition. These data suggested that $A G B 1$ controls developmental plasticity in response to drought stress. (Table 1 and Figure 3A).

Rice $d 1$ (rice G $\alpha$-null mutant, or rga1) mutants exhibit a higher photosynthetic rate, root to shoot ratio and greater stomatal conductance under drought stress (Ferrero-Serrano and Assmann, 2016; Ferrero-Serrano et al., 2018). Deletion of a rice G $\gamma$ gene is associated with a quantitative trait locus qPE9-1 that enhances drought tolerance including reduced water loss and higher stomatal conductance. In contrast, G $\beta$ RNAi line showed a hypersensitive phenotype to drought which included higher water loss and lower survival rate after drought treatment (Zhang et al., 2015). The transcripts of some stress-related genes were highly upregulated in the $G \gamma$ mutant, whereas expression of $\mathrm{ABA}$ synthesis genes and qPE9-1 expression are mis-regulated in G $\beta$ mutant under drought stress (Zhang et al., 2015). These observations suggest that $G \gamma$ is a negative regulator while $\mathrm{G} \beta$ promotes the tolerance of drought response through the ABA-dependent pathway (Table 2 and Figure 3B). Seed-specific overexpression of $A G G 3$ also improved drought stress tolerance in Camelina sativa (Roy Choudhury et al., 2014). 
TABLE 1 | Response of Arabidopsis G protein mutants to environmental stresses and the stress hormone ABA.

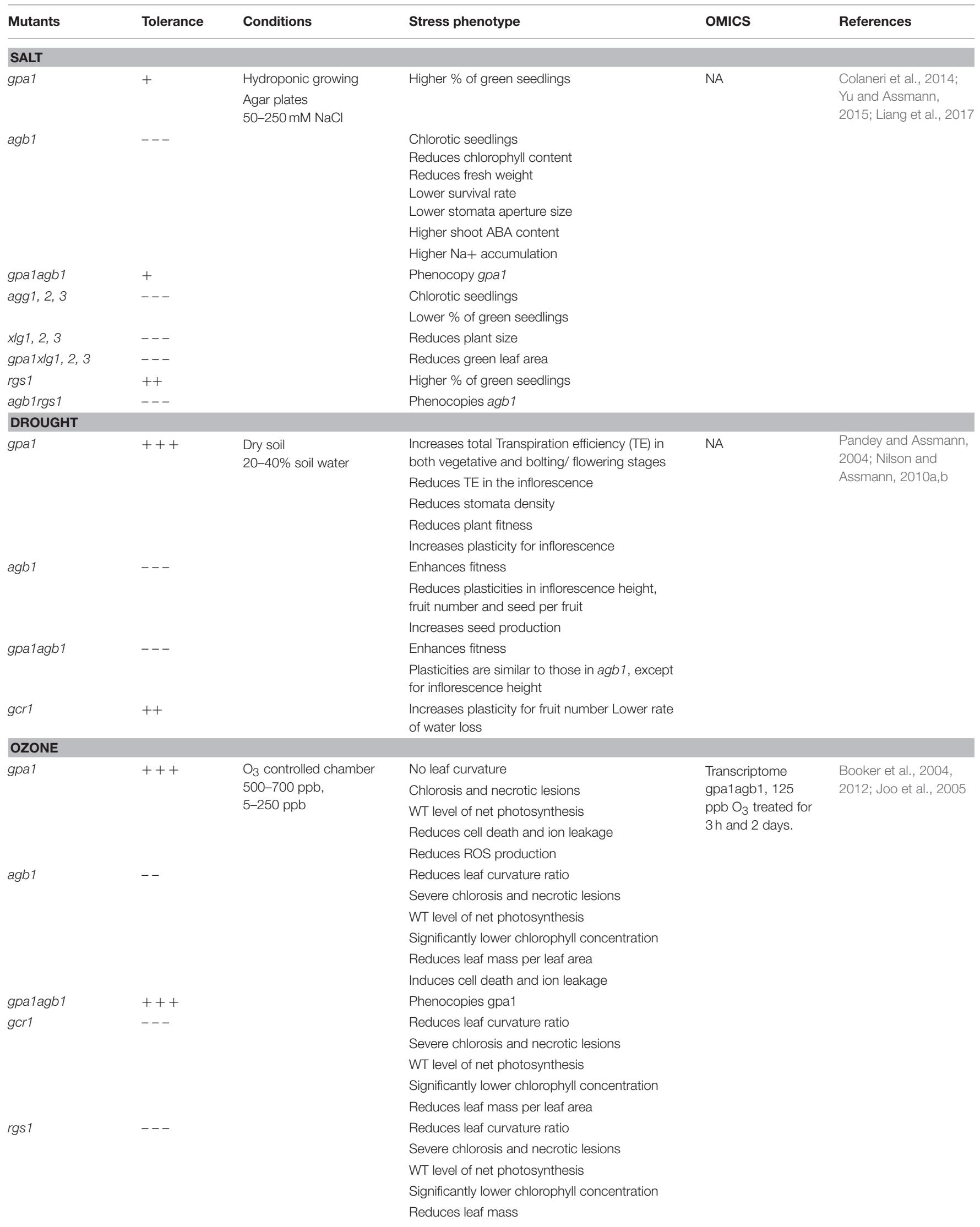


TABLE 1 | Continued

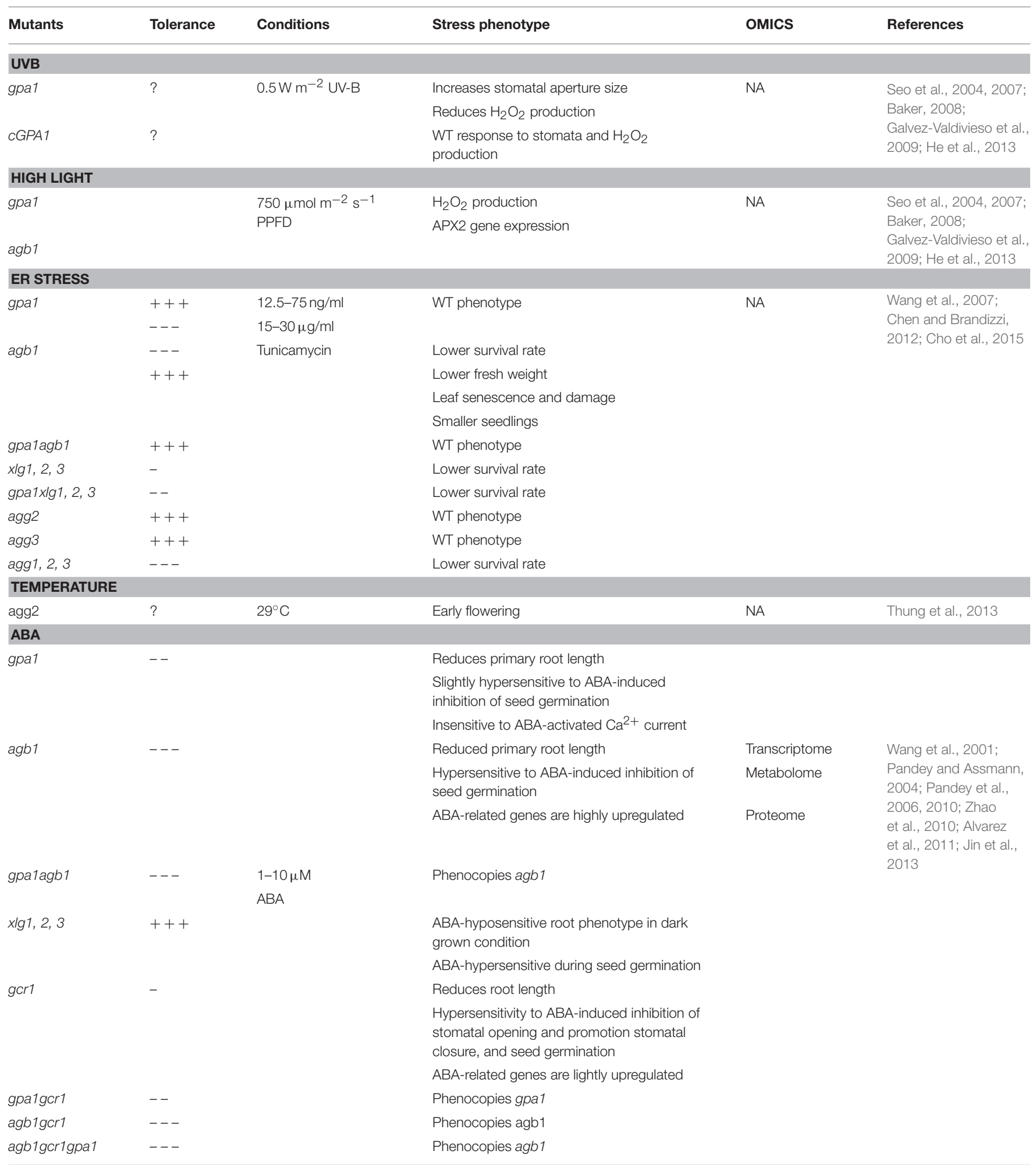

\section{Stress Hormone ABA}

The phytohormone ABA mediates some of the drought and salt stress responses altered by $\mathrm{G}$ protein mutations (Lee and Luan,
2012). In guard cells, ABA decreases the influx of potassium ions and reduces the turgor pressure of guard cells, which causes stomatal closure and suppresses light-induced stomatal opening. 

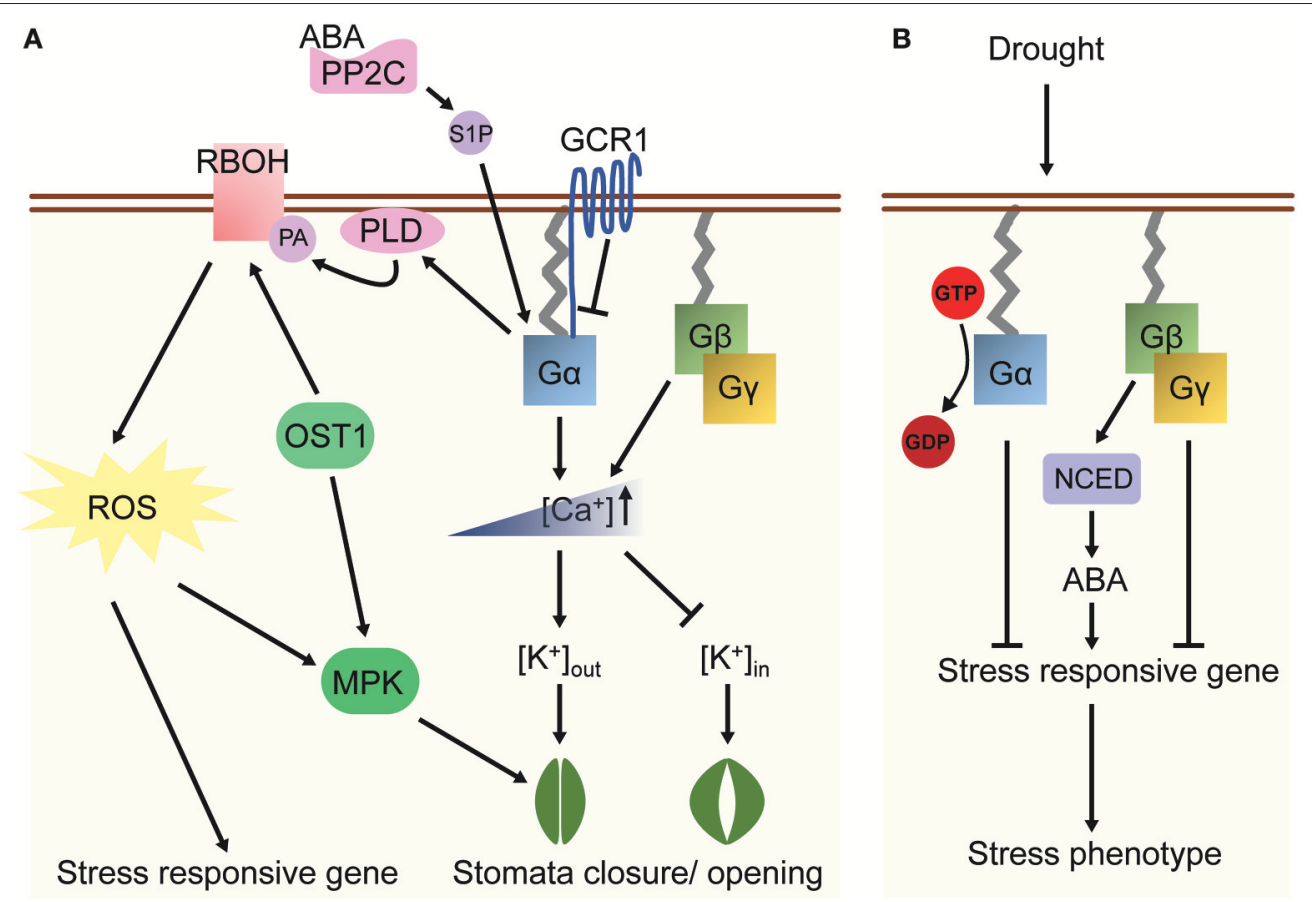

FIGURE 3 | A model of G protein-related ABA and drought responses in plants. (A) ABA coupled with PP2C induces Ga activation through Sphingosine-1-phosphate $(\mathrm{S} 1 \mathrm{P})$, leading to the $\left[\mathrm{Ca}^{2+}\right.$ ] elevation in cytosol. $\mathrm{G} \beta \gamma$ also increases the cytosolic concentration of $\mathrm{Ca}^{2+}$ under $\mathrm{ABA}$ treatment. Followed by changes of $\mathrm{K}^{+}$in- and outflux, the stomatal closure or opening is then regulated by ABA-dependent G protein signaling. In addition, Ga interacts with phospholipase D $(P L D)$ and its lipid product phosphatidic acid (PA), which subsequently affects the activity of RBOH. ROS and MAP kinase (MPK) signal are up-regulated correspondingly in ABA response. (B) $G$ protein signaling is involved in drought response in rice. $G \alpha$ and $G \gamma$ suppress the expression of stress responsive genes, while $G \beta$ increases their expression through ABA-mediated pathways. The arrows indicate activation and the bars indicate suppression.

Arabidopsis gpa1 mutants had decreased sensitivity to the ABA inhibition of stomatal opening and lacked ABA inhibition of inward $\mathrm{K}^{+}$channels and $\mathrm{pH}$-independent $\mathrm{ABA}$ activation of anion channels (Wang et al., 2001). The gcrl mutant showed hypersensitivity to ABA-induced and sphingosine-1-phosphate (S1P)-induced inhibition of stomatal opening and promotion of stomatal closure, suggesting that GCR1 and GPA1 have an opposite effect in ABA signaling in guard cells (Pandey and Assmann, 2004; Pandey et al., 2006). Besides the regulation of $\mathrm{K}^{+}$inward channel, ABA induces the opening of $\mathrm{Ca}^{2+}$ channel in guard cells. The ABA-induced $\mathrm{Ca}^{2+}$-channel opening was disrupted in the gpal mutants, which led to reduced ROS production in response to ABA (Zhang et al., 2011). Nonetheless, gpal mutant showed WT-response to $\mathrm{H}_{2} \mathrm{O}_{2}$ inhibition of stomatal opening and promotion of stomatal closure, indicating that GPA1 regulates $\mathrm{ABA}$ reception and ROS production and consequently in the impairment of $\mathrm{Ca}^{2+}$-channel activation (Figure 3A). In contrast, agg1, agg2, and agg1,2 double mutants all exhibited WT responses to ABA in stomatal movement in the guard cells. However, agg3 mutants showed hypersensitivity to ABA inhibition of stomatal opening and the inward $\mathrm{K}^{+}$channel, which phenocopied agb1 phenotypes in response to ABA (Chakravorty et al., 2011). These observations suggested that $G \beta \gamma$ dimer are required for the ABA signaling in plants.

RGS1 and PLD $\alpha 1$ accelerate the GTPase activity of GPA1, and both RGS1 and GPA1 inhibit the phospholipase activity of
PLD $\alpha 1$ (Chen et al., 2003; Zhao and Wang, 2004). Interestingly, phosphatidic acid (PA), a second messenger derived from the lipid-hydrolyzing activity of $\operatorname{PLD} \alpha 1$, binds and inhibits the activity of RGS1 (Roy Choudhury and Pandey, 2017), forming a feedback regulatory loop among G protein complex, PLD $\alpha 1$ and PA. RGS1 serves as a positive regulator of ABA-mediated inhibition of seed germination, while PLD $\alpha 1$ plays a role in ABAregulated stomatal responses in a $G$ protein-dependent manner (Table 1 and Figure 3A) (Chen and Jones, 2004; Zhao and Wang, 2004; Mishra et al., 2006; Fan et al., 2008). Further, gpa1rgs1 and gpalpld 1 mutants showed the same phenotype as gpa1, whereas pld $\alpha 1$ rgs 1 mutants behaved similar to $p l d \alpha 1$ and WT in ABAinhibition of seed germination, suggesting that a combinational and complex interaction between PLD $\alpha 1$ and RGS1 with GPA1 regulate ABA response in plants (Roy Choudhury and Pandey, 2016).

\section{Ozone Stress}

Long-term exposure to ozone $\left(\mathrm{O}_{3}\right)$ suppresses plant growth and reduces net photosynthesis, which is considered to cause the reduction of crop yield by $5-15 \%$ annually (Ludwikow and Sadowski, 2008). Ozone enters plants during the gas exchange through stomata, degrades to reactive oxygen species in extracellular space, and causes foliar bronzing, irregular lesions and bleaching. In addition to the chlorotic and necrotic symptoms, acute ozone treatment in Arabidopsis results in 
TABLE 2 | Response of G protein mutants to environmental stresses and ABA in plants other than Arabidopsis.

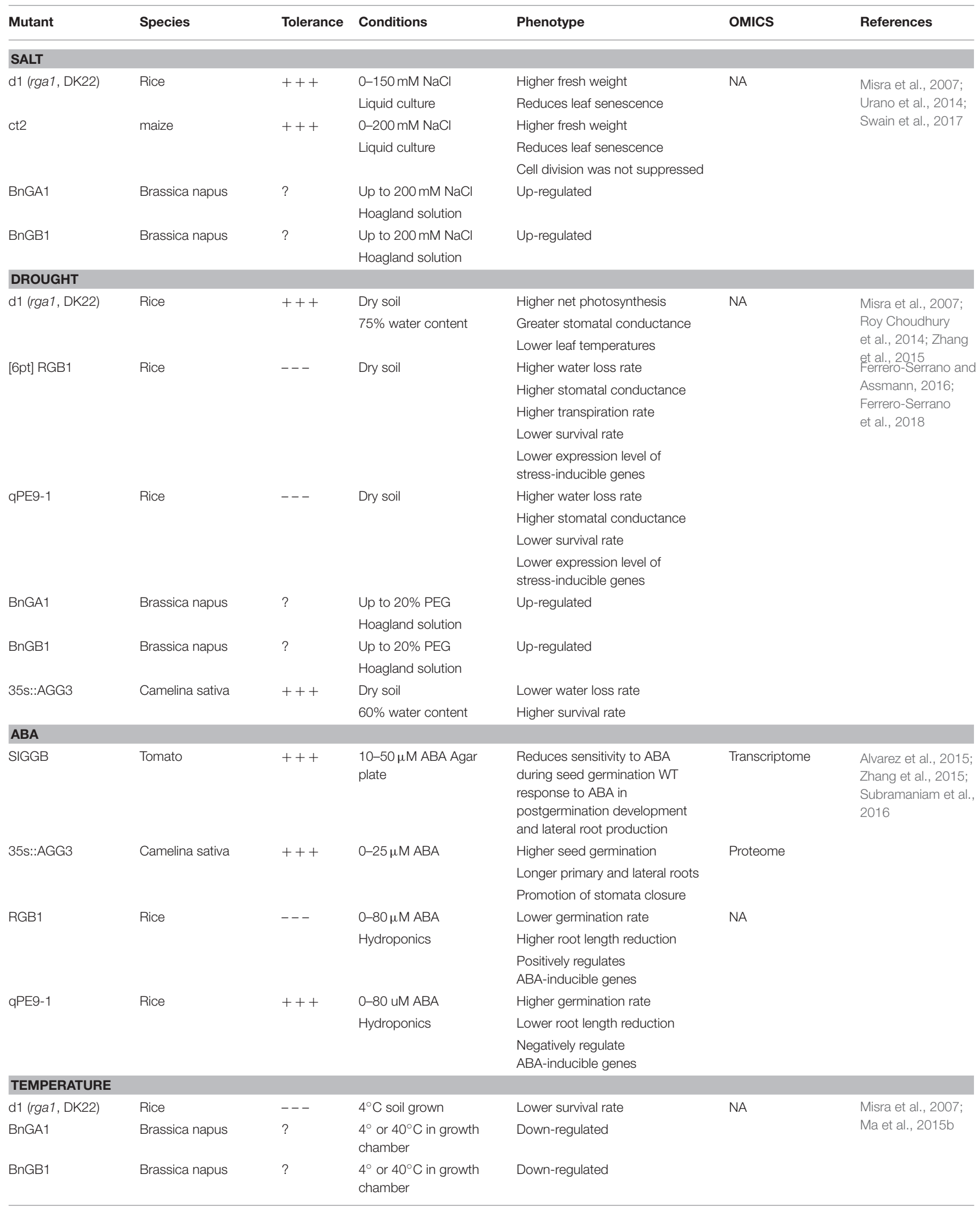



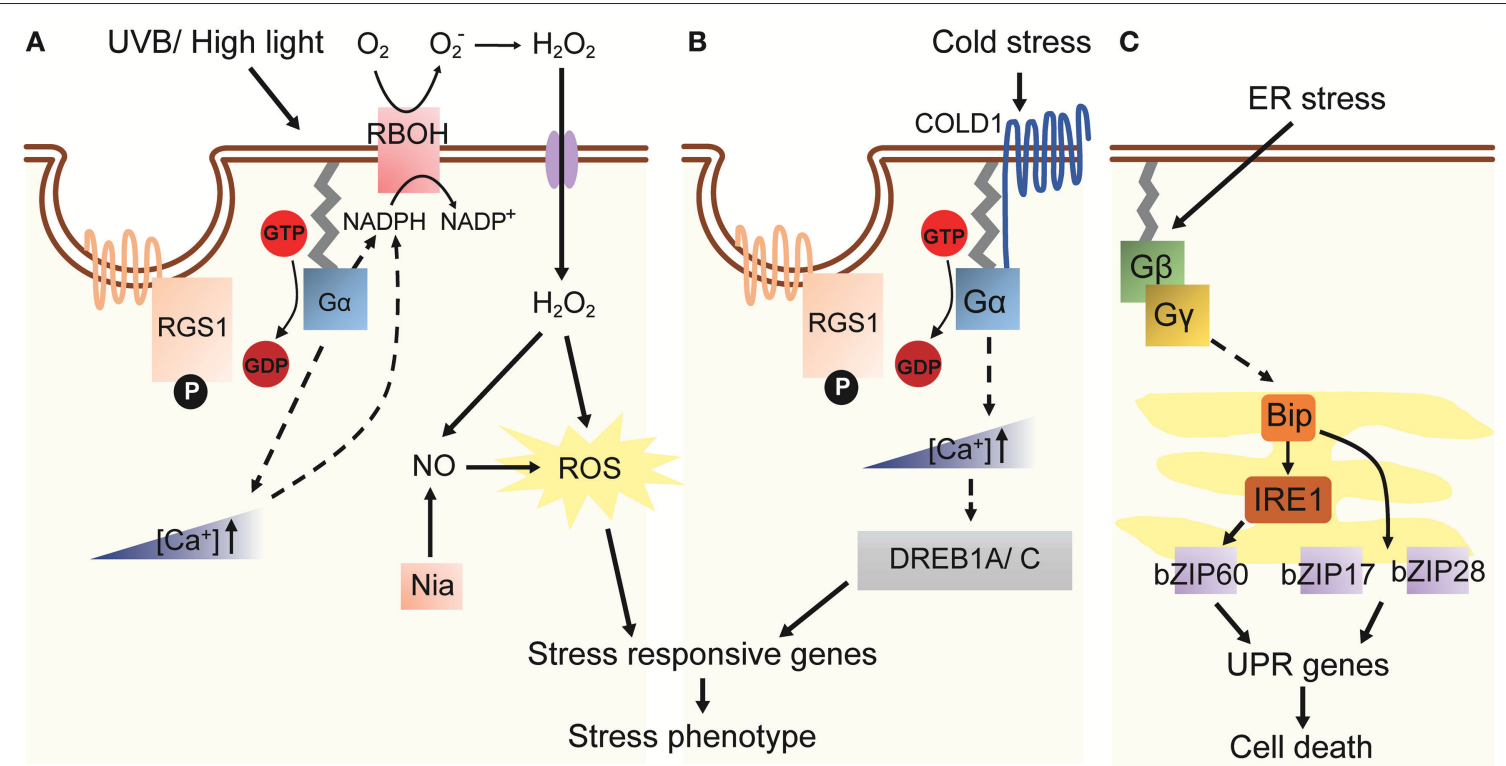

FIGURE 4 | A model of G protein-related high light, cold and ER stress in plants. (A) AtGPA1, labeled as G $\alpha$ in the figure, is activated by high light or UVB stress in Arabidopsis. AtGPA1 induces a transient increase of $\left[\mathrm{Ca}^{2+}\right]$ in cytosol and RBOH activation and the following NO-dependent ROS accumulation. The downstream stress response genes are subsequently up-regulated, which eventually cause the stress phenotype. (B) Cold stress response through G protein pathway. COLD1 interacts with AtGPA1 and elevates cytosolic $\left[\mathrm{Ca}^{2+}\right]$ concentration at low temperature. The expression of stress-related TF DREB1A/C is upregulated, which leads to the up-regulation of stress responsive genes (Ma et al., 2015a). (C) ER stress induces the expression of G $\beta \gamma$-regulated Bip, IRE1, several bZIPs and UPR genes.

abnormal morphology such as dwarfism and leaf curling. Genetic evidence suggested that $\mathrm{G}$ proteins transduce extracellular $\mathrm{O}_{3}$ signals to intracellular signaling molecules (Booker et al., 2004; Joo et al., 2005). Arabidopsis gpal and gpalagb1 mutants did not display curling leaf phenotype after $\mathrm{O}_{3}$ treatments (Table 1). gpa1 mutation also reduced ion leakage and cell death caused by $\mathrm{O}_{3}$-induced oxidative bursts, while agb1 mutant oppositely displayed hypersensitivity and intolerance to $\mathrm{O}_{3}$ treatment. Differential response to ROS production in $\mathrm{G}$ protein mutants, mainly gpal and agb1, could explain the molecular mechanism underlying the different sensitivities to ozone (Booker et al., 2004). $\mathrm{O}_{3}$ causes a biphasic production of ROS occurring from early and late time points. AtrbohD and AtrbohF, membrane-associated NADPH oxidases, trigger the initial ROS signal in adjacent cells, while the late ROS signal was related to tissue damage-associated components. The early and late responses both disappeared in gpal mutants while only the early response was undetectable in agb1 mutants (Joo et al., 2005). These suggested that GPA1 and AGB1 are both required for the initial ROS signaling in plants, and GPA1 is responsible for the following intercellular signaling and cell death. A transcriptome analysis with various concentrations of $\mathrm{O}_{3}$ revealed that the transcripts of GPA1, AGB1, and RGS1 genes were transiently induced by $\mathrm{O}_{3}$. However, most of the gene expression changes were similar among WT, gpa1, $a g b 1$, and gpalagbl double mutants. Further studies beyond transcriptional regulation are required to bridge the gap between physiological changes and molecular mechanisms underlying $\mathrm{G}$ proteins regulatory signaling in response to $\mathrm{O}_{3}$ (Booker et al., 2012).

\section{UVB Stress and High Light}

Depletion of the $\mathrm{O}_{3}$ layer has increased the level of high energy UVB radiation, harming most living organisms (Frohnmeyer, 2003). G proteins in mammalian and plant cells are involved in UVB signal transduction (Seo et al., 2004, 2007). In guard cells, UVB radiation induces $\mathrm{H}_{2} \mathrm{O}_{2}$ and nitrogen oxide (NO) generation that causes stomatal closure (He et al., 2013). The UVB-induced stomatal closure did not occur in Arabidopsis gpal mutant, suggesting $\mathrm{G} \alpha$ as a positive regulator of guard cell response to UVB radiation. GPA1 acts as an upstream modulator of $\mathrm{H}_{2} \mathrm{O}_{2}$ and $\mathrm{NO}$, because gpal mutant generates significantly lower levels of $\mathrm{H}_{2} \mathrm{O}_{2}$ and $\mathrm{NO}$ under UVB treatment and does not alter stomatal closure induced by these small molecule mediators. The genetic evidence combined with atrbohD/atrbohF (defect in $\mathrm{H}_{2} \mathrm{O}_{2}$ production) mutants and nia1-2/nia2-5 (defect in NO production) mutants, $\mathrm{G} \alpha$ is further confirmed to act as an upstream positive regulator of $\mathrm{H}_{2} \mathrm{O}_{2}$-dependent $\mathrm{NO}$ production in in UVB induced stomata closure (He et al., 2013; Figure 4A).

Likewise, plants grown in natural environment are usually exposed to high light (HL) condition and consequently absorb more light energy than required for photosynthesis, therefore the excess excitation energy has to be dissipated (Baker, 2008). In Arabidopsis, high-light stress causes $\mathrm{H}_{2} \mathrm{O}_{2}$ accumulation and induces ASCORBATE PEROXIDATSE 2 (APX2) gene expression. The expression of APX2 gene was 3-5 fold higher in gpa1 and agb1 mutants as compared to WT when grown under high light (Galvez-Valdivieso et al., 2009). Also, HL responsive genes including HSP17.6C-C1, HSP17.6B-C1, lipocalin, and RD20 all showed a similar expression pattern as APX2 in gpa1 and agb1 mutants (Galvez-Valdivieso et al., 2009). These suggested that 
$\mathrm{G}$ proteins are a negative regulator to initiate the downstream pathways under HL stress (Figure 4A).

\section{ER Stress}

Causes of ER stress are cellular accumulation of misfolded proteins and disruption of secretory protein synthesis and folding in the ER membrane (Howell, 2013). Two main sensors in response to ER stress have been identified, namely ERmembrane associated transcription factors (bZIP17 and bZIP28) and RNA splicing factors (IRE1A/B) (Howell, 2013). Cleaved bZIP28 shuttles into nucleus and induces the expression of UPRtarget genes, such as Immunoglobulin-Binding Protein 3 (BiP3), Protein Disulfide Isomerase $(P D B)$ and several other components comprising a protein-folding machinery in ER. Wang et al. proposed that Arabidopsis agb1-2 mutation ameliorates leaf senescence under tunicamycin (Tm) treatment, possibly due to reduced expression levels of $\mathrm{BiP} 3$ and $\mathrm{PDB}$ transcripts (Wang et al., 2007). However, later studies provided contradicting evidence whereby $a g b 1-1, a g b 1-2$, and $a g b 1-3$ all exhibited Tm-induced UPR-sensitive phenotype (Chen and Brandizzi, 2012; Cho et al., 2015) and higher BiP3 expression upon tunicamycin treatment. G $\beta$ and IRE1A/1B seemed to mediate UPR independently from each other, since G $\beta$ - and IRE1A/Bassociated UPR signaling pathways additively contributed to ER stress sensitivity (Chen and Brandizzi, 2012). Likewise, agg1,2,3 and $x \lg 1,2,3$ null mutants both showed similar Tm-induced phenotype, suggesting that G $\beta \gamma$ and XLGs were involved in UPR signaling pathway (Chakravorty et al., 2015; Urano et al., 2016a). The contradicting results from two studies might be due to the unresolved gene network of ER response, therefore requiring further studies to understand the comprehensive role of $\mathrm{G}$ proteins in ER stress (Figure 4C).

\section{Temperature Stress}

Drastic temperature changes occur often in recent years due to the global warming effect, causing irreversible damage to plants in some cases (Ohama et al., 2017). There are limited studies that focused on the $G$ protein signaling under temperature fluctuations. The agg2 mutant exhibited slightly earlier flowering phenotype in comparison to WT when grown at higher ambient temperature (around $29^{\circ} \mathrm{C}$ ) (Thung et al., 2013). Heterologous overexpression of $P$. sativum $\mathrm{G} \alpha$ or $\mathrm{G} \beta$ in tobacco plants resulted in tolerance to higher temperature during seed germination in T0 and T1 generation transformants (Misra et al., 2007). Heat Shock Factor A1 (HSFA1) is a master regulator in heat stress that initiates the transcriptional cascade of Heat Shock Proteins (HSPs) and other genes for the thermotolerance (Liu et al., 2011; Yoshida et al., 2011). In addition, heat-induced $\mathrm{Ca}^{2+}$ and ROS fluctuation may play a role in activation of HSFA1s in response to high temperature (Mittler et al., 2012). On the other hand, warmer ambient temperature sensing in plants requires PHYTOCHROME-INTERACTING FACTOR 4 (PIF4) transcription factor and changes in H2A.Z chromatin status (Kumar et al., 2012). While these transcriptional and epigenetic regulations have been well documented, how the central heatsensing mechanisms are linked to $G$ proteins-involved heat stress has yet to be investigated in detail.
In cold response, a quantitative trait locus (QTL) protein COLD1 interacts with RGA1 and slightly accelerates its GTPase activity to activate $\mathrm{Ca}^{2+}$ channels for conferring chilling tolerance in rice (Ma et al., 2015b). Given the fact that $\mathrm{Ca}^{2+}$ signaling mediates cellular responses to altered temperatures and cold1-1 and $d 1$ mutants showed a comparable dwarf phenotype which is related to mis-regulated $\mathrm{BR}$ and GA pathways, it would be interesting to investigate the molecular network linking hormone, cold response and $G$ protein signals (Figure 4B).

\section{SYSTEMS BIOLOGY APPROACH TO PLANT G PROTEIN RESEARCH IN ABIOTIC STRESS}

Studies on single gene or protein are insufficient to reveal the correlation or the crosstalk between different stress signaling pathways as stress response is a dynamic rather than a static cellular process within a single organism and across different organisms. Moreover, abiotic stress responses in plants involve multiple signaling processes coordinately. Omics studies have the highest potential to uncover the spatiotemporal signaling events for plant stress responses. Various systems biology approaches, for example, transcriptomics, metabolomics, proteomics and interactome have been employed to understand the $G$ protein signaling in abiotic stress responses. These systematic methodologies allow us to not only discover new gene functions in a complex cellular environment, but also characterize genome-scale relationships between genotypes and phenotypes deeply. In this chapter, we discuss established and cutting-edge techniques of OMICs approaches which are applicable to $\mathrm{G}$ protein studies.

\section{Transcriptome}

Manipulating massive amounts of transcriptomic data help us systematically grasp co-regulatory modes of gene expressions by G protein pathways, environmental changes and potentially the involvement of phytohormones. In Arabidopsis, gpal and gcr 1 mutations dramatically alter the expression pattern of abiotic stress-related genes, mainly genes related to transcription factors, secondary metabolism and hormone responses (Chakraborty et al., 2015a,b). Likewise, many stress-related genes were misregulated in the rice $\mathrm{G} \alpha$-null mutant $d 1$ (Jangam et al., 2016; Ferrero-Serrano et al., 2018). Besides these transcriptomic researches, Pandey et al. utilized microarray to comprehensively collect gene expression profiles in G protein mutants treated with or without ABA, then a theoretical Boolean framework was applied to categorize the regulatory modes of each of gene expression changes by gpal or agbl mutations as well as ABA treatment (Pandey et al., 2010). The Boolean model enumerated 9 possible G-protein and ABA signaling pathways and 142 regulatory modes (Pandey et al., 2010). This approach not only confirmed the classical mechanisms of $\mathrm{G}$ protein signaling but also provided new insight into system specificity of $G$ protein signaling in various cell types. Nonetheless, since gene expression patterns are generally more complex than having only two states $(0,1)$, data discretization sometimes leads to information loss. In 
addition, time-series gene expression makes large scale Boolean networks applications difficult. Therefore, it is necessary to collect even more data and apply various methods for modeling gene expression data.

\section{Metabolome}

Despite the intensive researches on physiological changes in $\mathrm{G}$ protein mutants under various stresses, information on global profiling of metabolites in G protein mutants in stress condition has remained limited. Metabolomics is a highthroughput approach to enable quantitative and comprehensive identification of large numbers of small metabolic compounds and their dynamic changes to extracellular stimuli. A timecourse metabolomics in gpal and WT guard cells identified 85 metabolic compounds and their dynamic changes after ABA treatment. ABA treatment significantly altered 56 and 43 out of 85 metabolites in WT and gpal guard cells, respectively (Jin et al., 2013). Among them, different temporal modules have been found in gpal vs. WT, including $\mathrm{Ca}^{2+}$ and other hormone signaling pathways, suggesting $\mathrm{ABA}$ serves as an upstream signal to trigger $G$ protein signaling (Jin et al., 2013).

\section{Proteome}

Abundance of transcripts often does not reflect changes in protein abundance. Since proteins are the final products of most genes, proteomes permit a thorough understanding of $\mathrm{G}$ protein signaling induced by different stress environments. Few studies have focused on changes in total protein abundance in roots, guard cells and seeds of Arabidopsis G $\alpha$ mutants and WT (Zhao et al., 2010; Alvarez et al., 2011). iTRAQ, a quantitative proteome approach, identified dozens of polypeptides of which abundance is cooperatively changed by $A B A$ and $G$ protein signaling in guard cells and roots. Novel G protein functions such as ER body formation and intracellular trafficking may shed light on new roles of $\mathrm{G} \alpha$ in Arabidopsis. These proteins include proteins related to intracellular trafficking in roots and to photosynthesis in guard cells. These two studies revealed how tissue specificity is involved in different $G$ protein functions in plants (Zhao et al., 2010; Alvarez et al., 2011). The seed proteome from overexpressed AtAGG3 transgenic Camelina sativa has been investigated by liquid chromatography (LC)based quantitative proteomics approach (Alvarez et al., 2015). In addition to proteins which are associated to hormone regulation, seed size and drought tolerance consistent with its physiological observation, proteins related to heavy metal responses have been identified, suggesting the involvement of AGG3 in heavy metal tolerance (Alvarez et al., 2015). However, limited total number of proteins (around 1,500-2,000 proteins in each report) were found in these studies, most of which are abundant proteins in the plastids, which might result in loss of information and bias toward data interpretation. Methods to achieve higher sensitivity and accuracy, such as optimal enrichment, fractionation and protein digestion protocols, could be employed for increasing the coverage of low abundant proteins.

\section{Interactome}

Proteomics approaches have been developed to identify not only protein abundance related to $G$ protein signaling, but also interacting partners of $\mathrm{G}$ protein subunits. Two yeast-twohybrid ( $\mathrm{Y} 2 \mathrm{H}$ ) based interactome studies identified hundreds of $\mathrm{G}$ protein-interacting partners (Klopffleisch et al., 2011; Jones et al., 2014). Among them, Klopffleisch et al. (2011) comprehensively screened for interacting partners of Arabidopsis G protein subunits, and a following study has found that salt stress-related proteins as an overrepresented group (Colaneri et al., 2014). A $\mathrm{Y} 2 \mathrm{H}$ experiment was carried out for identifying the binding partners of XLGs. Seventy-two potential proteins were found to interact with XLG1, 2, and 3 and more than $70 \%$ of them were confirmed to bind with XLGs in vivo using BiFC. The results not only provided new insight into XLG's newly identified binding partners which participated in G-proteins mediated salt response, but also provided valuable stress-related protein set for further studies. However, the detailed mechanism still remains unclear (Liang et al., 2017). Y2H method only detects the direct interactions between bait and prey proteins, although plausible indirect interactions can be deduced from in silico network construction. Moreover, protein-protein interactions are a dynamic process and sometimes the post-translational modification such as phosphorylation or ubiquitination is critical for the interaction. Hence, an immunoprecipitation (IP)-MS based interactome was established to detect the time- and glucose- dependent RGS1 interacting networks (Jaiswal et al., 2016). One hundred nineteen proteins were identified as RGS1 interactors, among which 93 were novel targets associated with transport, stress and metabolism at low glucose levels, and vascular trafficking and signal transduction at high glucose levels, respectively (Jaiswal et al., 2016). More recently, Yu et al. (2018) utilized co-IP and liquid chromatography (LC)-MS to isolate and identify AGB1-assoicated proteins. A total of 103 candidate AGB1-associated proteins were identified including all of the $\mathrm{G}$ protein subunits except XLG1, receptor-like kinase, $\mathrm{Ca}^{2+}$ signaling-related proteins and 14-3-3-like proteins. Among them, FER was confirmed to physically interact with AGB1 by using $\mathrm{BiFC}$ and was involved in ABA-regulated stomata opening and closure in a G-protein dependent manner. However, the AGB1assoicated proteins in the control condition did not differ from those identified in the salt treatment condition, suggesting that the AGB1-dependent salt response signaling was likely involved in the more downstream pathways (Yu et al., 2018).

\section{NOVEL APPROACHES TO STUDY ABIOTIC STRESS RESPONSE- TIME-COURSE OR CELL-TYPE SPECIFIC NETWORK CONSTRUCTION/ PTM/ CHIP-SEQ TF NETWORK}

The above-mentioned systematic approaches greatly improved our knowledge in plant abiotic stress responses and the involvement of $\mathrm{G}$ protein pathways, however the application of these advanced approaches is still limited to specific cases such as signals evoked by ABA or some stress treatments. With 
the importance and complexity of $\mathrm{G}$ proteins-by-environment relationship, more profound and broader studies are required. This section describes novel approaches that have yet to be applied to plant $G$ protein signaling.

\section{High Resolution Spatiotemporal Gene Regulatory Network to Reveal Multiple Phases in Response to Abiotic Stress}

Given the rapid development of OMICs tools, an increasing number of researches are utilizing these techniques to construct comprehensive visualization of stress responses in plants. These techniques enable detection and quantification of dynamic intracellular changes from gene expressions to post-translational modifications of proteins during the course of stress response and development. For example, Geng et al captured spatiotemporal transcriptional changes in different cell types during Arabidopsis root development under salt treatment (Geng et al., 2013). Their high-resolution transcriptional map demonstrated that ABA signaling pathways spatially regulate salt stress-specific transcriptional programs in selected layers of Arabidopsis root tissue to promote growth recovery from high salinity. In contrast, sodium toxicity independently regulates many tissue- and time-specific transcriptional responses which are associated with water transport and hydrophobic cell wall tissue (Casparian strip) formation. By combining highly resolved time series transcriptome and a dynamic modeling, an integrative visualization of the temporal response to drought in Arabidopsis can be achieved. Notably, Bayesian network modeling of TF genes was applied to infer the differentially expressed gene regulatory networks that mediate the transition from the early to late stage of drought response (Bechtold et al., 2016). This approach has predicted that Agamous-Like 22 (AGL22) is a key hub in this regulatory network and the follow-up genetic studies confirmed that AGL22 regulates the transcriptional network during drought stress, linking changes in primary metabolism to the initiation of drought response. As the large amounts of transcriptomic dataset are available publicly, meta-analysis has emerged to aim for compelling the results across independent studies and extract the most robust and useful information. A study has employed meta-analysis and meta-regression to normalize public transcriptomic dataset from Arabidopsis in response to water loss (Rest et al., 2016). This novel approach identified the genes with small differential responses consistently in all the analyzed dataset, which contributed to stress tolerance.

\section{ChIP-Sequencing to Identify Whole Genome TFs Network and Epigenetic Regulations in Abiotic Stress Condition}

ChIP-sequencing identifies binding targets of multiple TFs and their directly regulatory genes. Through integrated-TF networks of ABA-induced drought response, Song et al identified 21 ABArelated TFs and novel genome-wide binding sites in Arabidopsis (Song et al., 2016). An extensive feedback of ABA regulatory network was predicted by analyzing chronological changes of differentially expressed genes and differentially binding motifs under ABA treatment. Based on the prediction, multi-TF binding could be a criterion for prioritizing the further characterization of unknown genes with genetic methods in plants. Several novel TFs that are involved in $\mathrm{ABA}$ and salt regulatory signaling were uncovered with the following proof-of-concept experiments.

In addition, ChIP-sequencing is capable of detecting chromatin dynamics and variations. Environmental factors induce epigenetic changes such as chromatin modification, which are tightly correlated with transcriptional response. For example, drought, flooding, temperature fluctuation and high salinity affect the methylation or acetylation of DNA and histones (Pandey et al., 2016; Asensi-Fabado et al., 2017). A genome-wide survey of methylation status in response to salt stress in rice revealed that the level of hypo-methylation is associated with the expression level of DNA demethylases, and this led to different degrees of salt tolerance in two contrasting rice lines (Ferreira et al., 2015). It was also found that histone deacetylase HDA6 is crucial for $\mathrm{H} 3 \mathrm{~K} 4 \mathrm{me} 3$-mediated gene activation, changing the sensitivity toward salt stress in Arabidopsis (Sani et al., 2013). Moreover, the expression of drought stress responsive genes showed a positive correlation with the level of histone modifications $\mathrm{H} 3 \mathrm{~K} 9 \mathrm{ac}$ and $\mathrm{H} 3 \mathrm{~K} 4 \mathrm{me} 3$ during the course of drought treatment, and the drought treatment resulted in genome-wide variations in $\mathrm{H} 3 \mathrm{~K} 4 \mathrm{me} 1, \mathrm{H} 3 \mathrm{~K} 4 \mathrm{me} 2$ and $\mathrm{H} 3 \mathrm{~K} 4 \mathrm{me} 3$ in Arabidopsis (van Dijk et al., 2010; Kim et al., 2012). Another whole genome association study focusing on temperature response revealed that the variation of DNA methylation patterns was strongly associated with genetic variations and their growing temperatures (Dubin et al., 2015). Further researches are required to investigate if $G$ protein pathways regulate these epigenetic changes and how the epigenetic changes are related to transcriptional changes and physiological outcomes in $\mathrm{G}$ protein mutants.

\section{Post-translational Modification (PTM)- Phosphoproteome}

PTM, particularly phosphorylation, participates in the signal transduction in abiotic stress conditions. Several quantitative phosphoproteomes of drought stressed plants (Umezawa et al., 2004, 2013; Wang et al., 2013) revealed that SUCROSE NON-FERMENTING 1-RELATED KINASES 2 (SNRK2) family transmits ABA-induced signals through phosphorylation of downstream substrates. By comparing the phosphoproteome of snrk2 mutants and WT, Umezawa et al identified new direct substrates of ABA-activated SNRK2 (Umezawa et al., 2013). Similarly, a phosphoproteome research in crops in response to drought has identified phosphorylation events of some common stress-related proteins such as $\mathrm{Ca}^{2+}$ signal-related proteins and HSPs (Rampitsch and Bykova, 2012). A time-course phosphoproteome from rice roots under salt stress showed that the phosphorylated stress-responsive proteins are differentially expressed with prolonged salt stress. Several novel membrane proteins including aquaporins and photosystem II-related proteins were phosphorylated in response to salt condition (Chitteti and Peng, 2007). In summary, proteomics and PTM identification could shed light on uncovering new protein targets that are involved in stress tolerance as well as identifying novel phosphorylation events within signal transduction pathways. G proteins regulate ABA-response genes as well as $\mathrm{Ca}^{2+}$ signaling pathways. Future studies should investigate the whole genome 


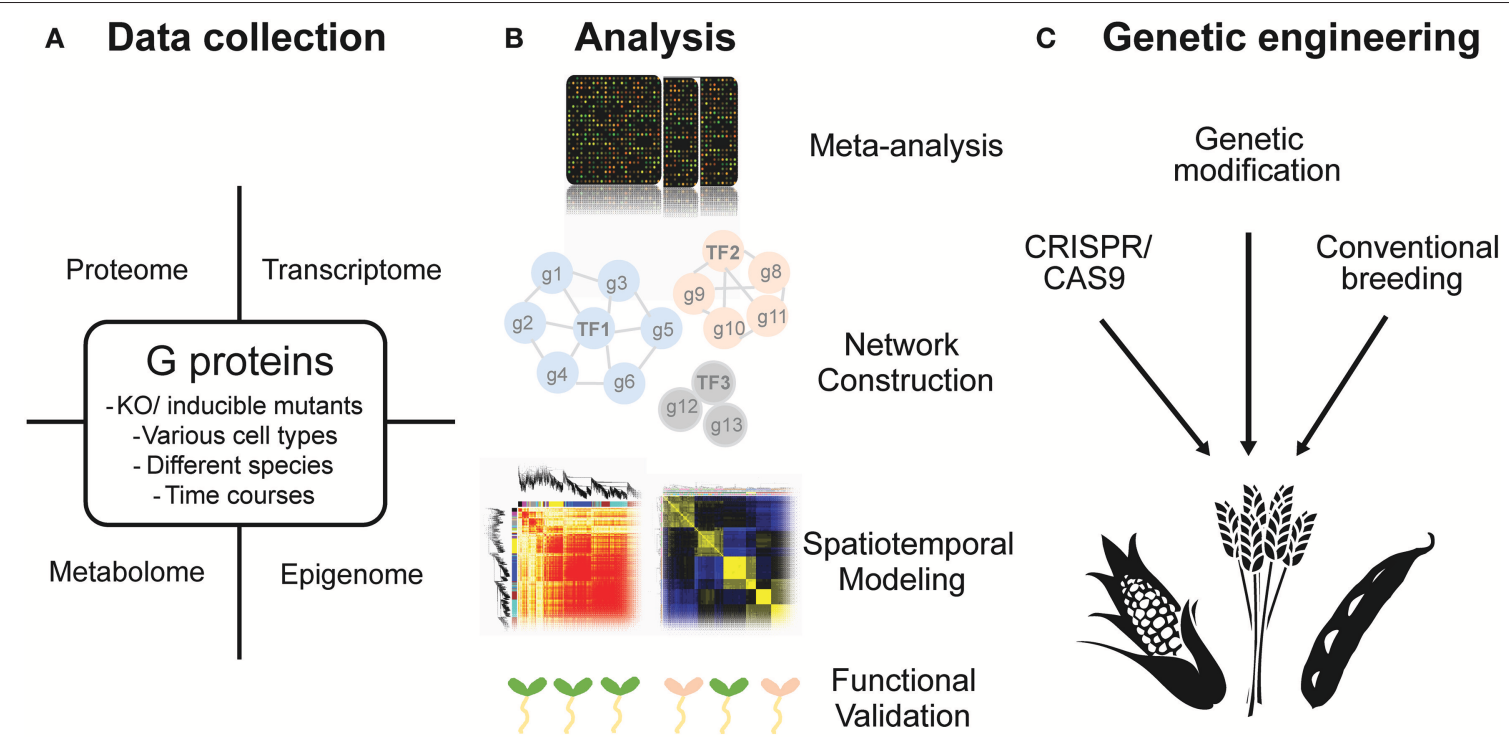

FIGURE 5 | Potential perspectives in the research of G protein regulated stress response in plants. (A) Different types of OMICS data such as transcriptome, proteome, epigenome and metabolome could be sampled from various tissues or along with different developmental stages in plants. (B) Several systematic-analytical techniques could be taken including meta-analysis, unsupervised and supervised network construction, spatiotemporal modeling and functional validating by phenomes. (C) The ultimate goal is to utilize the knowledge obtained from model plants and to create stress tolerant crops by cutting-edge biotechnologies.

PTM status in G protein mutants in comparison to WT under various stresses.

\section{Deep Learning in OMICs Researches}

As discussed, OMICs data are one of the higher order dimensional data with complex multi-level structures, and therefore they have become promising input data for machine learning and deep learning approaches for analysis and interpretation of biological data. Indeed, machine learning has been implemented in abiotic stress research recently (Ma et al., 2014). A prediction model was built based on the training with public abiotic stresses transcriptomic dataset to recognize common or distinct patterns. The comparative gene expression network was applied to find distinct and novel gene candidates related to abiotic stress response, two mutants of which demonstrated salt hypersensitive phenotype. Moreover, several deep learning techniques such as deep neural networks $(\mathrm{DNN})$, convolutional neural networks $(\mathrm{CNN})$ and recurrent neural networks (RNN) have been applied to biomedical, drug discovery and fundamental biology researches to identify new regulators from integrated big OMICs data. For example, Chen et al (Chen et al., 2016) applied DNN to gene expression data to infer expression levels of 21000 target genes from 1,000 landmark genes and showed highly precise prediction of gene expression model. Furthermore, Simm et al (Simm et al., 2018) applied DNN to reanalyze high-throughput bioimages for predicting the specificity and activity of new drugs, boosting the speed of drug discovery. Likewise, a CNN-based algorithm has been implemented to learn regulatory sequences of quantitative trait loci and disease-associated variants from large-scale chromatin-profiling data, which resulted in better understanding of complex disease-associated SNPs (Zhou and Troyanskaya, 2015). Recently, A RNN-based integrative model has been designed for predicting molecular state in E. coli. This model is trained based on multi-omics and interaction data and then predicts multi-omics expression under untested novel conditions. As a result, it could precisely predict and integrate different layers of OMICs data and could be broadly applicable for biological discovery (Kim et al., 2016). Given the fact that increasing numbers of OMICs data from different stress conditions and of easily adapted deep learning libraries are being available, a new possibility will be opened to reanalyze OMICs data and then build a training model based on well-developed algorithms for discovering new regulators associated with $G$ proteins in plants.

\section{CONCLUSIONS AND FUTURE PERSPECTIVES}

Evidence to date leave no doubt that $\mathrm{G}$ proteins are involved in abiotic stress response in many plants. However, to access the in-depth knowledge on how $G$ proteins are involved in stress response, more genome-wide analyses are still needed. As discussed, the methodologies and experimental designs in systems biology help us answer the complex questions in abiotic stress responses (Figure 5). We could also implement similar strategies to open questions in G protein science. Examples of these questions are listed below.

\section{Time Resolution}

Stress response is by no means a steady-state response and could be well-explained by the changes captured in just a few 
A

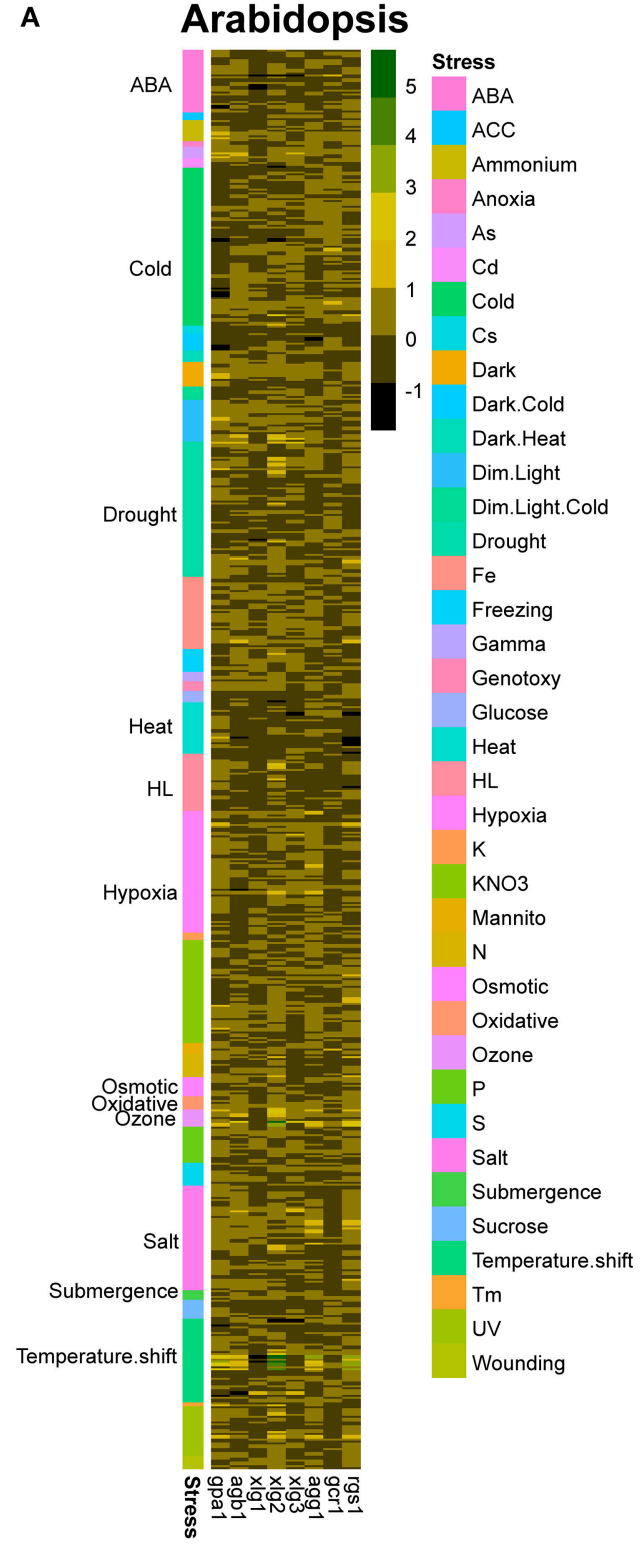

B

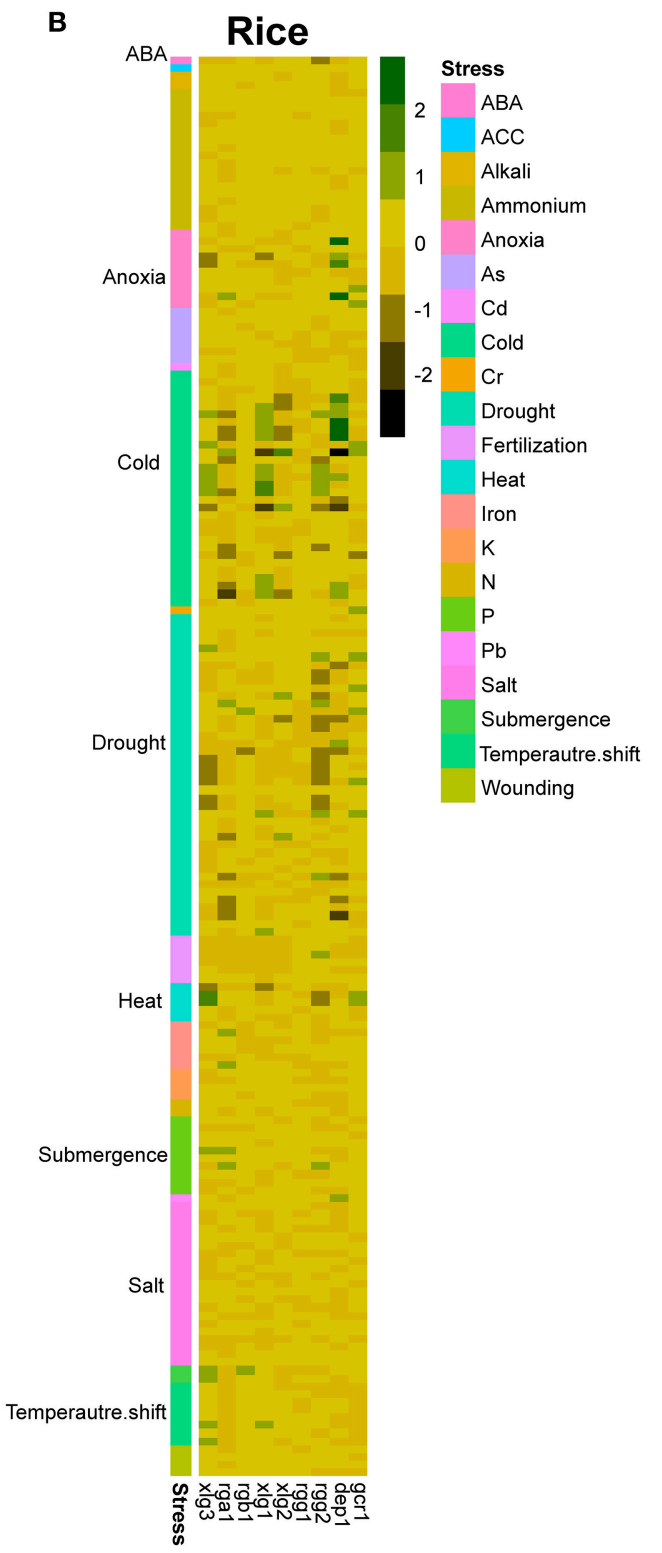

FIGURE 6 | Expression patterns of G protein-related genes in response to various abiotic stresses. Expression profiles of G protein-related genes in (A) Arabidopsis and (B) rice under various stress conditions including chemical treatments, hormone treatments, various light intensity and quality, various temperature treatments, osmotic stress and drought stress are obtained from GENEVESIGATOR. The expression data were $\log _{2}$ transformed, and $p$-values were calculated by the comparison between each treatment and the control condition. Data with $p<0.05$ was selected.

time points under stress treatment. However, stress responses in plants are extremely dynamic along the time. Consequently, the time resolution of exact kinetic changes in $G$ proteins and their regulated genes after stress signal perception would be an interesting topic in the future.

\section{Cell Type and Tissue Specificities}

Previous studies suggested that $G$ proteins acquired different specificities in different cell types in response to ABA. Plants also show different responses to various abiotic stresses in different cell types. Hence, it would be interesting to elucidate $\mathrm{G}$ protein regulatory network in distinct cell types in different developmental stages under stress condition. Besides, there are several public databases regarding gene expression patterns in different root or seed cell types along the course of development. By comparing gene expressions changed by abiotic stresses and $G$ proteins using the publicly-available data, we might gain insight into the common and distinct regulatory modules associated with $\mathrm{G}$ protein signaling under stress conditions.

\section{Beyond Transcriptional Regulation}

By analyzing the expression patterns of $G$ protein genes from public data, it is clear that the expression levels of $G$ protein genes are relatively consistent, only exhibiting some slight 
changes under certain conditions (Figure 6). While molecular mechanisms for stress-related phenotypes in $G$ protein mutants are unclear yet, it is evident that $G$ proteins regulate downstream proteins through the changes of PTM status. In addition, PTMs particularly phosphorylation would regulate the activity of $\mathrm{G}$ proteins themselves. Therefore, investigating the genome-wide PTM status is particularly important to understand the signaling flow and activation state of $\mathrm{G}$ protein complex.

\section{Mechanisms to Integrate Various Stresses}

It has been a long-standing question how plants sense different stress conditions and activate different stress response genes. Abiotic stress responses are mediated by several signaling pathways: some are shared by different stresses while others are unique to a specific stress type. $G$ proteins are involved in many stress tolerance, but little is known about their selectivity. A possible strategy adopted by plants would be switching interacting partners based on the type of stresses. More specifically, $G$ proteins may form a protein complex with different regulatory partners upon different types of stresses. Interactome or proteome experiments could be established to determine the protein components associated with $G$ protein complex under different stress conditions.

\section{Stress Response Mechanisms Conserved Across Species}

To date the evidence show that part of the $G$ protein response to stress is similar in Arabidopsis and several crops including rice and maize (Urano et al., 2014; Ma et al., 2015b; Zhang et al., 2015; Ferrero-Serrano and Assmann, 2016). However, phylogenetic analyses indicated that some $G$ protein components were lacked or duplicated in different species, therefore it would be interesting to investigate if $\mathrm{G}$ protein-related stress responses remain conserved. Systems biology strategies would also shed light on how plants evolve to tolerate different and constantly changing environmental stresses.

\section{CONCLUSION}

In conclusion, with the development of OMICs tools and integration of massive amounts of quantitative dataset, we are able to understand the molecular and biochemical aspects of $\mathrm{G}$ protein regulation in various environmental stresses. The long-term goal is to integrate the outcomes from previous conventional studies and future genome-wide studies to find new stress tolerance gene candidates and mechanisms in plants. The new knowledge will help us to genetically design crops which are able to flourish in changing environment.

\section{AUTHOR CONTRIBUTIONS}

T-YW and DU contributed to the conception, design and writing of the manuscript.

\section{ACKNOWLEDGMENTS}

This work is supported by Temasek Life Sciences Laboratory Ltd. We would like to thank Dr. Alan M. Jones, Ms. Richalynn Leong, and Ms. Krishnamoorthi Shalini for careful reading of the manuscript.

\section{REFERENCES}

Alvarez, S., Hicks, L. M., and Pandey, S. (2011). ABA-dependent and -independent G-protein signaling in arabidopsis roots revealed through an iTRAQ proteomics approach. J. Proteome Res. 10, 3107-3122. doi: 10.1021/pr2001786

Alvarez, S., Roy Choudhury, S., Sivagnanam, K., Hicks, L. M., and Pandey, S. (2015). Quantitative proteomics analysis of camelina sativa seeds overexpressing the AGG3 gene to identify the proteomic basis of increased yield and stress tolerance. J. Proteome Res. 14, 2606-2616. doi: 10.1021/acs.jproteome.5b00150

Aranda-Sicilia, M. N., Trusov, Y., Maruta, N., Chakravorty, D., Zhang, Y., and Botella, J. R. (2015). Heterotrimeric G proteins interact with defenserelated receptor-like kinases in Arabidopsis. J. Plant Physiol. 188, 44-48. doi: 10.1016/j.jplph.2015.09.005

Asensi-Fabado, M. A., Amtmann, A., and Perrella, G. (2017). Plant responses to abiotic stress: the chromatin context of transcriptional regulation. Biochim. Biophys. Acta 1860, 106-122. doi: 10.1016/j.bbagrm.2016.07.015

Assmann, S. M. (2004). Plant G proteins, phytohormones, and plasticity: three questions and a speculation. Sci. STKE 2004:re20. doi: $10.1126 /$ stke.2642004re20

Baker, N. R. (2008). Chlorophyll fluorescence: a probe of photosynthesis in vivo. Annu. Rev. Plant Biol. 59, 89-113. doi: 10.1146/annurev.arplant.59.032607.092759

Bechtold, U., Penfold, C. A., Jenkins, D. J., Legaie, R., Moore, J. D., Lawson, T., et al. (2016). Time-series transcriptomics reveals that AGAMOUS-LIKE22 affects primary metabolism and developmental processes in drought-stressed Arabidopsis. Plant Cell 28, 345-366. doi: 10.1105/tpc.15.00910

Booker, F., Burkey, K., Morgan, P., Fiscus, E., and Jones, A. (2012). Minimal influence of G-protein null mutations on ozone-induced

changes in gene expression, foliar injury, gas exchange and peroxidase activity in Arabidopsis thaliana L. Plant, Cell Environ. 35, 668-681. doi: 10.1111/j.1365-3040.2011.02443.x

Booker, F. L., Burkey, K. O., Overmyer, K., and Jones, A. M. (2004). Differential responses of G-protein Arabidopsis thaliana mutants to ozone. New Phytol. 162, 633-641. doi: 10.1111/j.1469-8137.2004.01081.x

Bradshaw, A. D. (1965). Evolutionary significance of phenotypic plasticity in plants. Adv. Genet. 13, 115-155. doi: 10.1016/S0065-2660(08)60048-6

Cao-Pham, A. H., Urano, D., Ross-Elliott, T. J., and Jones, A. M. (2018). Nudge-nudge, WNK-WNK (kinases), say no more? New Phytol. doi: $10.1111 /$ nph.15276

Chakraborty, N., Sharma, P., Kanyuka, K., Pathak, R. R., Choudhury, D., Hooley, R., et al. (2015a). G-protein $\alpha$-subunit (GPA1) regulates stress, nitrate and phosphate response, flavonoid biosynthesis, fruit/seed development and substantially shares GCR1 regulation in A. thaliana. Plant Mol. Biol. 89, 559-576. doi: 10.1007/s11103-015-0374-2

Chakraborty, N., Singh, N., Kaur, K., and Raghuram, N. (2015b). G-protein signaling components GCR1 and GPA1 mediate responses to multiple abiotic stresses in Arabidopsis. Front. Plant Sci. 6:1000. doi: 10.3389/fpls.2015. 01000

Chakravorty, D., Gookin, T. E., Milner, M. J., Yu, Y., and Assmann, S. M. (2015). Extra-large $G$ proteins expand the repertoire of subunits in Arabidopsis heterotrimeric G protein signaling. Plant Physiol. 169, 512-529. doi: 10.1104/pp.15.00251

Chakravorty, D., Trusov, Y., Zhang, W., Acharya, B. R., Sheahan, M. B., McCurdy, D. W., et al. (2011). An atypical heterotrimeric G-protein gamma-subunit is involvedin guard cell $\mathrm{K}^{+}$-channel regulation and morphologicaldevelopment in Arabidopsis thaliana. Plant J. 67, 840-851. doi: 10.1111/j.1365-313X.2011.04638.x 
Chen, J. G., and Jones, A. M. (2004). AtRGS1 function in Arabidopsis thaliana. Meth. Enzymol. 389, 338-350. doi: 10.1016/S0076-6879(04)89020-7

Chen, J. G., Willard, F. S., Huang, J., Liang, J., Chasse, S. A., Jones, A. M., et al. (2003). A seven-transmembrane RGS protein that modulates plant cell proliferation. Science 301, 1728-1731. doi: 10.1126/science.1087790

Chen, Y., and Brandizzi, F. (2012). AtIRE1A/AtIRE1B and AGB1 independently control two essential unfolded protein response pathways in Arabidopsis. Plant J. 69, 266-277. doi: 10.1111/j.1365-313X.2011.04788.x

Chen, Y., Li, Y., Narayan, R., Subramanian, A., and Xie, X. (2016). Gene expression inference with deep learning. Bioinformatics 32, 1832-1839. doi: 10.1093/bioinformatics/btw074

Chitteti, B. R., and Peng, Z. (2007). Proteome and phosphoproteome differential expression under salinity stress in rice (Oryza sativa) roots. J. Proteome Res. 6, 1718-1727. doi: 10.1021/pr060678z

Cho, Y., Yu, C. Y., Iwasa, T., and Kanehara, K. (2015). Heterotrimeric G protein subunits differentially respond to endoplasmic reticulum stress in Arabidopsis. Plant Signal. Behav. 10:e1061162. doi: 10.1080/15592324.2015.1061162

Colaneri, A. C., Tunc-Ozdemir, M., Huang, J. P., and Jones, A. M. (2014). Growth attenuation under saline stress is mediated by the heterotrimeric $\mathrm{G}$ protein complex. BMC Plant Biol. 14:129. doi: 10.1186/1471-2229-14-129

Dubin, M. J., Zhang, P., Meng, D., Remigereau, M. S., Osborne, E. J., Paolo Casale, F., et al. (2015). DNA methylation in Arabidopsis has a genetic basis and shows evidence of local adaptation. Elife 4:e05255. doi: 10.7554/eLife.05255

Fan, L. M., Zhang, W., Chen, J. G., Taylor, J. P., Jones, A. M., and Assmann, S. M. (2008). Abscisic acid regulation of guard-cell $\mathrm{K}^{+}$and anion channels in Gbeta- and RGS-deficient Arabidopsis lines. Proc. Natl. Acad. Sci. U.S.A. 105, 8476-8481. doi: 10.1073/pnas.0800980105

Ferreira, L. J., Azevedo, V., Maroco, J., Oliveira, M. M., and Santos, A. P. (2015). Salt tolerant and sensitive rice varieties display differential methylome flexibility under salt stress. PLoS ONE 10:e0124060. doi: 10.1371/journal.pone.0124060

Ferrero-Serrano, Á., and Assmann, S. M. (2016). The $\alpha$-subunit of the rice heterotrimeric $\mathrm{G}$ protein, RGAl, regulates drought tolerance during the vegetative phase in the dwarf rice mutant d1. J. Exp. Bot. 67, 3433-3443. doi: 10.1093/jxb/erw183

Ferrero-Serrano, Á., Su, Z., and Assmann, S. M. (2018). Illuminating the role of the $G \alpha$ heterotrimeric $G$ protein subunit, RGA1, in regulating photoprotection and photoavoidance in rice. Plant. Cell Environ. 41, 451-468. doi: $10.1111 /$ pce. 13113

Frohnmeyer, H. (2003). Ultraviolet-B radiation-mediated responses in plants. Balancing damage and protection. Plant Physiol. 133, 1420-1428. doi: 10.1104/pp.103.030049

Galvez-Valdivieso, G., Fryer, M. J., Lawson, T., Slattery, K., Truman, W., Smirnoff, N., et al. (2009). The high light response in Arabidopsis Involves ABA signaling between vascular and bundle sheath cells. Plant Cell 21, 2143-2162. doi: $10.1105 /$ tpc. 108.061507

Gao, Y., Wang, S., Asami, T., and Chen, J. G. (2008). Loss-of-function mutations in the Arabidopsis heterotrimeric G-protein $\alpha$ subunit enhance the developmental defects of brassinosteroid signaling and biosynthesis mutants. Plant Cell Physiol. 49, 1013-1024. doi: 10.1093/pcp/pcn078

Geng, Y., Wu, R., Wee, C. W., Xie, F., Wei, X., Chan, P. M., et al. (2013). A spatiotemporal understanding of growth regulation during the salt stress response in Arabidopsis. Plant Cell 25, 2132-2154. doi: 10.1105/tpc.113.112896

Hackenberg, D., McKain, M. R., Lee, S. G., Roy Choudhury, S., McCann, T., Schreier, S., et al. (2017). G $\alpha$ and regulator of G-protein signaling (RGS) protein pairs maintain functional compatibility and conserved interaction interfaces throughout evolution despite frequent loss of RGS proteins in plants. New Phytol. 216, 562-575. doi: 10.1111/nph.14180

He, J.-M., Ma, X.-G., Zhang, Y., Sun, T.-F., Xu, F.-F., Chen, Y.-P., et al. (2013). Role and interrelationship of $\mathrm{G}$ Protein, hydrogen peroxide, and nitric oxide in ultraviolet B-induced stomatal closure in Arabidopsis leaves. Plant Physiol. 161, 1570-1583. doi: 10.1104/pp.112.211623

Howell, S. H. (2013). Endoplasmic reticulum stress responses in plants. Annu. Rev. Plant Biol. 64, 477-499. doi: 10.1146/annurev-arplant-050312-120053

Huey, R. B. (2002). Plants versus animals: do they deal with stress in different ways? Integr. Comp. Biol. 42, 415-423. doi: 10.1093/icb/42.3.415

Jaiswal, D. K., Werth, E. G., McConnell, E. W., Hicks, L. M., and Jones, A. M. (2016). Time-dependent, glucose-regulated Arabidopsis regulator of G-protein Signaling 1 network. Curr. Plant Biol. 5, 25-35. doi: 10.1016/j.cpb.2015.11.002
Jangam, A. P., Pathak, R. R., and Raghuram, N. (2016). Microarray analysis of Rice d1 (RGA1) mutant reveals the potential role of G-protein alpha subunit in regulating multiple abiotic stresses such as drought, salinity, heat, and cold. Front. Plant Sci. 7:11. doi: 10.3389/fpls.2016.00011

Jin, X., Wang, R. S., Zhu, M., Jeon, B. W., Albert, R., Chen, S., et al. (2013). Abscisic acid-responsive guard cell metabolomes of Arabidopsis wild-type and gpal G-protein mutants. Plant Cell 25, 4789-4811. doi: 10.1105/tpc.113.119800

Jones, A. M., Xuan, Y., Xu, M., Wang, R. S., Ho, C. H., Lalonde, S., et al. (2014). Border control- A membrane-linked interactome of Arabidopsis. Science 344, 711-716. doi: 10.1126/science. 1251358

Joo, J. H., Wang, S., Chen, J. G., Jones, A. M., and Fedoroff, N. V. (2005). Different signaling and cell death roles of Heterotrimeric G protein $\alpha$ and $\beta$ subunits in the Arabidopsis oxidative stress response to Ozone. Plant Cell 17, 957-970. doi: 10.1105/tpc.104.029603

Kaziro, Y., Itoh, H., Kozasa, T., Nakafuku, M., and Satoh, T. (1991). Structure and function of signal-transducing GTP-binding proteins. Annu. Rev. Biochem. 60, 349-400. doi: 10.1146/annurev.bi.60.070191.002025

Kim, J. M., To, T. K., Ishida, J., Matsui, A., Kimura, H., and Seki, M. (2012). Transition of chromatin status during the process of recovery from drought stress in Arabidopsis thaliana. Plant Cell Physiol. 53, 847-856. doi: $10.1093 / \mathrm{pcp} / \mathrm{pcs} 053$

Kim, M., Rai, N., Zorraquino, V., and Tagkopoulos, I. (2016). Multi-omics integration accurately predicts cellular state in unexplored conditions for Escherichia coli. Nat. Commun. 7:13090. doi: 10.1038/ncomms13090

Klopffleisch, K., Phan, N., Augustin, K., Bayne, R. S., Booker, K. S., Botella, J. R., et al. (2011). Arabidopsis G-protein interactome reveals connections to cell wall carbohydrates and morphogenesis. Mol. Syst. Biol. 7, 532-532. doi: $10.1038 / \mathrm{msb} .2011 .66$

Kumar, S. V., Lucyshyn, D., Jaeger, K. E., Alós, E., Alvey, E., Harberd, N. P., et al. (2012). Transcription factor PIF4 controls the thermosensory activation of flowering. Nature 484, 242-245. doi: 10.1038/nature10928

Lee, S. C., and Luan, S. (2012). ABA signal transduction at the crossroad of biotic and abiotic stress responses. Plant, Cell Environ. 35, 53-60. doi: 10.1111/j.1365-3040.2011.02426.x

Liang, X., Ding, P., Lian, K., Wang, J., Ma, M., Li, L., et al. (2016). Arabidopsis heterotrimeric $\mathrm{G}$ proteins regulate immunity by directly coupling to the FLS2 receptor. Elife 5:e13568. doi: 10.7554/eLife.13568

Liang, Y., Gao, Y., and Jones, A. M. (2017). Extra large G-protein interactome reveals multiple stress response function and partner-dependent XLG subcellular localization. Front. Plant Sci. 8:1015. doi: 10.3389/fpls.2017.01015

Liu, H. C., Liao, H. T., and Charng, Y. Y. (2011). The role of class A1 heat shock factors (HSFA1s) in response to heat and other stresses in Arabidopsis. Plant, Cell Environ. 34, 738-751. doi: 10.1111/j.1365-3040.2011.02278.x

Ludwikow, A., and Sadowski, J. (2008). Gene networks in plant ozone stress response and tolerance. J. Integr. Plant Biol. 50, 1256-1267. doi: 10.1111/j.1744-7909.2008.00738.x

Ma, C., Xin, M., Feldmann, K. A., and Wang, X. (2014). Machine learning-based differential network analysis: a study of stress-responsive transcriptomes in Arabidopsis. Plant Cell 26, 520-537. doi: 10.1105/tpc.113. 121913

Ma, Y., Dai, X., Xu, Y., Luo, W., Zheng, X., Zeng, D., et al. (2015b). COLD1 confers chilling tolerance in rice. Cell 160, 1209-1221. doi: 10.1016/j.cell.2015.01.046

Ma, Y.-n., Chen, M., Xu, D.-b., Fang, G.-n., Wang, E.-h., Gao, S.-q., et al. (2015a). G-protein $\beta$ subunit AGB1 positively regulates salt stress tolerance in Arabidopsis. J. Integr. Agric. 14, 314-325. doi: 10.1016/S2095-3119(14)60777-2

Mishra, G., Zhang, W., Deng, F., Zhao, J., and Wang, X. (2006). A bifurcating pathway directs abscisic acid effects on stomatal closure and opening in Arabidopsis. Science 312, 264-266. doi: 10.1126/science.1123769

Misra, S., Wu, Y., Venkataraman, G., Sopory, S. K., and Tuteja, N. (2007). Heterotrimeric G-protein complex and G-protein-coupled receptor from a legume (Pisum sativum): role in salinity and heat stress and cross-talk with phospholipase C. Plant J. 51, 656-669. doi: 10.1111/j.1365-313X.2007. 03169.x

Mittler, R., Finka, A., and Goloubinoff, P. (2012). How do plants feel the heat? Trends Biochem. Sci. 37, 118-125. doi: 10.1016/j.tibs.2011.11.007

Nilson, S. E., and Assmann, S. M. (2010a). Heterotrimeric G proteins regulate reproductive trait plasticity in response to water availability. New Phytol. 185, 734-746. doi: 10.1111/j.1469-8137.2009.03120.x 
Nilson, S. E., and Assmann, S. M. (2010b). The -Subunit of the Arabidopsis heterotrimeric G Protein, GPA1, is a regulator of transpiration efficiency. Plant Physiol. 152, 2067-2077. doi: 10.1104/pp.109.148262

Ohama, N., Sato, H., Shinozaki, K., and Yamaguchi-Shinozaki, K. (2017). Transcriptional regulatory network of plant heat stress response. Trends Plant Sci. 22, 53-65. doi: 10.1016/j.tplants.2016.08.015

Oki, K., Kitagawa, K., Fujisawa, Y., Kato, H., and Iwasaki, Y. (2009). Function of $\alpha$ subunit of heterotrimeric $\mathrm{G}$ protein in brassinosteroid response of rice plants. Plant Signal. Behav. 4, 126-128. doi: 10.4161/psb.4.2.7627

Pandey, G., Sharma, N., Sahu, P. P., and Prasad, M. (2016). Chromatin-based epigenetic regulation of plant abiotic stress response. Curr. Genomics 17, 490-498. doi: 10.2174/1389202917666160520103914

Pandey, S., and Assmann, S. M. (2004). The Arabidopsis putative G proteincoupled receptor GCR1 interacts with the G protein alpha subunit GPA1 and regulates abscisic acid signaling. Plant Cell 16, 1616-1632. doi: $10.1105 /$ tpc.020321

Pandey, S., Chen, J. G., Jones, A. M., and Assmann, S. M. (2006). Gprotein complex mutants are hypersensitive to abscisic acid regulation of germination and postgermination development. Plant Physiol. 141, 243-256. doi: $10.1104 /$ pp.106.079038

Pandey, S., and Vijayakumar, A. (2018). Emerging themes in heterotrimeric G-protein signaling in plants. Plant Sci. 270, 292-300. doi: 10.1016/j.plantsci.2018.03.001

Pandey, S., Wang, R. S., Wilson, L., Li, S., Zhao, Z., Gookin, T. E., et al. (2010). Boolean modeling of transcriptome data reveals novel modes of heterotrimeric G-protein action. Mol. Syst. Biol. 6, 372. doi: 10.1038/msb.2010.28

Rampitsch, C., and Bykova, N. V. (2012). The beginnings of crop phosphoproteomics: exploring early warning systems of stress. Front. Plant Sci. 3:144. doi: 10.3389/fpls.2012.00144

Rest, J. S., Wilkins, O., Yuan, W., Purugganan, M. D., and Gurevitch, J. (2016). Meta-analysis and meta-regression of transcriptomic responses to water stress in Arabidopsis. Plant J. 85, 548-560. doi: 10.1111/tpj.13124

Roy Choudhury, S., and Pandey, S. (2016). The role of PLD $\alpha 1$ in providing specificity to signal-response coupling by heterotrimeric G-protein components in Arabidopsis. Plant J. 86, 50-61. doi: 10.1111/tpj.13151

Roy Choudhury, S., and Pandey, S. (2017). Phosphatidic acid binding inhibits RGS1 activity to affect specific signaling pathways in Arabidopsis. Plant J. 90, 466-477. doi: 10.1111/tpj.13503

Roy Choudhury, S., Riesselman, A. J., and Pandey, S. (2014). Constitutive or seedspecific overexpression of Arabidopsis G-protein $\gamma$ subunit 3 (AGG3) results in increased seed and oil production and improved stress tolerance in Camelina sativa. Plant Biotechnol. J. 12, 49-59. doi: 10.1111/pbi.12115

Sani, E., Herzyk, P., Perrella, G., Colot, V., and Amtmann, A. (2013). Hyperosmotic priming of Arabidopsis seedlings establishes a long-term somatic memory accompanied by specific changes of the epigenome. Genome Biol. 14, R59. doi: 10.1186/gb-2013-14-6-r59

Seo, M., Cho, C. H., Lee, Y. I., Shin, E. Y., Park, D., Bae, C. D., et al. (2004). Cdc42dependent mediation of $\mathrm{UV}$-induced $\mathrm{p} 38$ activation by $\mathrm{G}$ protein $\beta \gamma$ subunits. J. Biol. Chem. 279, 17366-17375. doi: 10.1074/jbc.M312442200

Seo, M., Lee, M. J., Heo, J. H., Lee, Y. I., Kim, Y., Kim, S. Y., et al. (2007). G protein $\beta \gamma$ subunits augment UVB-induced apoptosis by stimulating the release of soluble heparin-binding epidermal growth factor from human keratinocytes. J. Biol. Chem. 282, 24720-24730. doi: 10.1074/jbc.M702343200

Simm, J., Klambauer, G., Arany, A., Steijaert, M., Wegner, J. K., Gustin, E., et al. (2018). Repurposing high-throughput image assays enables biological activity prediction for drug discovery. Cell Chem. Biol. 25, 611.e3-618.e3. doi: 10.1016/j.chembiol.2018.01.015

Song, L., Huang, S. C., Wise, A., Castanoz, R., Nery, J. R., Chen, H., et al. (2016). A transcription factor hierarchy defines an environmental stress response network. Science 354:aag1550. doi: 10.1126/science.aag1550

Subramaniam, G., Trusov, Y., Lopez-Encina, C., Hayashi, S., Batley, J., and Botella, J. R. (2016). Type B heterotrimeric G protein? $\gamma$-subunit regulates auxin and ABA signaling in tomato. Plant Physiol. 170, 1117-1134. doi: $10.1104 /$ pp. 15.01675

Swain, D. M., Sahoo, R. K., Srivastava, V. K., Tripathy, B. C., Tuteja, R., and Tuteja, N. (2017). Function of heterotrimeric G-protein $\gamma$ subunit RGG1 in providing salinity stress tolerance in rice by elevating detoxification of ROS. Planta 245, 367-383. doi: 10.1007/s00425-016-2614-3
Thung, L., Chakravorty, D., Trusov, Y., Jones, A. M., and Botella, J. R. (2013). Signaling specificity provided by the Arabidopsis thaliana heterotrimeric G-protein $\gamma$ subunits AGG1 and AGG2 is partially but not exclusively provided through transcriptional regulation. PLOS ONE 8:e58503. doi: 10.1371/journal.pone.0058503

Tunc-Ozdemir, M., Urano, D., Jaiswal, D. K., Clouse, S. D., and Jones, A. M. (2016). Direct modulation of heterotrimeric $\mathrm{G}$ protein-coupled signaling by a receptor kinase complex. J. Biol. Chem. 291, 13918-13925. doi: 10.1074/jbc.C116.736702 Ueguchi-Tanaka, M., Fujisawa, Y., Kobayashi, M., Ashikari, M., Iwasaki, Y., Kitano, H., et al. (2000). Rice dwarf mutant d1, which is defective in the alpha subunit of the heterotrimeric $\mathrm{G}$ protein, affects gibberellin signal transduction. Proc. Natl. Acad. Sci. U.S.A. 97, 11638-11643. doi: 10.1073/pnas.97.21.11638

Ullah, H., Chen, J.-G., Temple, B., Boyes, D. C., Alonso, J. M., Davis, K. R., et al. (2003). The $\beta$-subunit of the Arabidopsis G protein negatively regulates auxininduced cell division and affects multiple developmental processes. Plant Cell 15, 393-409. doi: 10.1105/tpc.006148

Ullah, H., Chen, J. G., Young, J. C., Im, K. H., Sussman, M. R., and Jones, A. M. (2001). Modulation of cell proliferation by heterotrimeric $G$ protein in Arabidopsis. Science 292, 2066-2069. doi: 10.1126/science.1059040

Umezawa, T., Sugiyama, N., Takahashi, F., Anderson, J. C., Ishihama, Y., Peck, S. C., et al. (2013). Genetics and phosphoproteomics reveal a protein phosphorylation network in the abscisic acid signaling pathway in Arabidopsis thaliana. Sci. Signal. 6:rs8. doi: 10.1126/scisignal.2003509

Umezawa, T., Yoshida, R., Maruyama, K., Yamaguchi-Shinozaki, K., and Shinozaki, K. (2004). SRK2C, a SNF1-related protein kinase 2, improves drought tolerance by controlling stress-responsive gene expression in Arabidopsis thaliana. Proc. Natl. Acad. Sci. U.S.A. 101, 17306-17311. doi: 10.1073/pnas.0407758101

Urano, D., Chen, J. G., Botella, J. R., and Jones, A. M. (2013). Heterotrimeric G protein signalling in the plant kingdom. Open Biol. 3, 120186-120186. doi: 10.1098/rsob.120186

Urano, D., Colaneri, A., and Jones, A. M. (2014). G $\alpha$ modulates salt-induced cellular senescence and cell division in rice and maize. J. Exp. Bot. 65, 6553-6561. doi: 10.1093/jxb/eru372

Urano, D., Dong, T., Bennetzen, J. L., and Jones, A. M. (2015). Adaptive evolution of signaling partners. Mol. Biol. Evol. 32, 998-1007. doi: 10.1093/molbev/msu404

Urano, D., Maruta, N., Trusov, Y., Stoian, R., Wu, Q., Liang, Y., et al. (2016a). Saltational evolution of the heterotrimeric $\mathrm{G}$ protein signaling mechanisms in the plant kingdom. Sci. Signal. 9:ra93. doi: 10.1126/scisignal.aaf9558

Urano, D., Miura, K., Wu, Q., Iwasaki, Y., Jackson, D., and Jones, A. M. (2016b) Plant morphology of heterotrimeric G protein mutants. Plant Cell Physiol. 57, 437-445. doi: 10.1093/pcp/pcw002

Urano, D., Phan, N., Jones, J. C., Yang, J., Huang, J., Grigston, J., et al. (2012). Endocytosis of the seven-transmembrane RGS1 protein activates Gprotein-coupled signalling in Arabidopsis. Nat. Cell Biol. 14, 1079-1088. doi: $10.1038 /$ ncb2568

van Dijk, K., Ding, Y., Malkaram, S., Riethoven, J. J., Liu, R., Yang, J., et al. (2010). Dynamic changes in genome-wide histone $\mathrm{H} 3$ lysine 4 methylation patterns in response to dehydration stress in Arabidopsis thaliana. BMC Plant Biol. 10:238. doi: 10.1186/1471-2229-10-238

Wang, L., Xu, Y. Y., Ma, Q. B., Li, D., Xu, Z. H., and Chong, K. (2006). Heterotrimeric $\mathrm{G}$ protein $\alpha$ subunit is involved in rice brassinosteroid response. Cell Res. 16, 916-922. doi: 10.1038/sj.cr.7310111

Wang, P., Xue, L., Batelli, G., Lee, S., Hou, Y. J., Van Oosten, M. J., et al. (2013). Quantitative phosphoproteomics identifies SnRK2 protein kinase substrates and reveals the effectors of abscisic acid action. Proc. Natl. Acad. Sci. U.S.A. 110, 11205-11210. doi: 10.1073/pnas.1308974110

Wang, S., Narendra, S., and Fedoroff, N. (2007). Heterotrimeric G protein signaling in the Arabidopsis unfolded protein response. Proc. Natl. Acad. Sci. U.S.A. 104, 3817-3822. doi: 10.1073/pnas.0611735104

Wang, X. Q., Ullah, H., Jones, A. M., and Assmann, S. M. (2001). G protein regulation of ion channels and abscisic acid signaling in Arabidopsis guard cells. Science 292, 2070-2072. doi: 10.1126/science.1059046

Yoshida, T., Ohama, N., Nakajima, J., Kidokoro, S., Mizoi, J., Nakashima, K., et al. (2011). Arabidopsis HsfA1 transcription factors function as the main positive regulators in heat shock-responsive gene expression. Mol. Genet. Genomics 286, 321-332. doi: 10.1007/s00438-011-0647-7 
Yu, Y., and Assmann, S. M. (2015). The heterotrimeric G-protein $\beta$ subunit, AGB1, plays multiple roles in the Arabidopsis salinity response. Plant, Cell Environ. 38, 2143-2156. doi: 10.1111/pce.12542

$\mathrm{Yu}, \mathrm{Y}$. , and Assmann, S. M. (2016). The effect of $\mathrm{NaCl}$ on stomatal opening in Arabidopsis wild type and agb1 heterotrimeric G-protein mutant plants. Plant Signal. Behav. 11, e1085275. doi: 10.1080/15592324.2015.1085275

Yu, Y., Chakravorty, D., and Assmann, S. M. (2018). The G Protein $\beta$-Subunit, AGB1, Interacts with FERONIA in RALF1-Regulated Stomatal Movement. Plant Physiol. 176, 2426-2440. doi: 10.1104/pp.17.01277

Zhang, D. P., Zhou, Y., Yin, J. F., Yan, X. J., Lin, S., Xu, W. F., et al. (2015). Rice Gprotein subunits qPE9-1 and RGB1 play distinct roles in abscisic acid responses and drought adaptation. J. Exp. Bot. 66, 6371-6384. doi: 10.1093/jxb/erv350

Zhang, L., Hu, G., Cheng, Y., and Huang, J. (2008). Heterotrimeric G protein $\alpha$ and $\beta$ subunits antagonistically modulate stomatal density in Arabidopsis thaliana. Dev. Biol. 324, 68-75. doi: 10.1016/j.ydbio.2008.09.008

Zhang, W., Jeon, B. W., and Assmann, S. M. (2011). Heterotrimeric G-protein regulation of ROS signalling and calcium currents in Arabidopsis guard cells. J. Exp. Bot. 62, 2371-2379. doi: 10.1093/jxb/erq424

Zhao, J., and Wang, X. (2004). Arabidopsis phospholipase D $\alpha 1$ interacts with the heterotrimeric G-protein $\alpha$-subunit through a motif analogous to the DRY motif in G-protein-coupled receptors. J. Biol. Chem. 279, 1794-1800. doi: 10.1074/jbc.M309529200
Zhao, Z., Stanley, B. A., Zhang, W., and Assmann, S. M. (2010). ABA-regulated $\mathrm{G}$ protein signaling in arabidopsis guard cells: a proteomic perspective. J. Proteome Res. 9, 1637-1647. doi: 10.1021/pr901011h

Zhou, J., and Troyanskaya, O. G. (2015). Predicting effects of noncoding variants with deep learning-based sequence model. Nat. Methods 12, 931-934. doi: $10.1038 /$ nmeth. 3547

Zhu, J.-K. (2002). Salt and drought stress signal transduction in plants. Annu. Rev. Plant Biol. 53, 247-273. doi: 10.1146/annurev.arplant.53.091401. 143329

Zhu, J.-K. (2016). Abiotic stress signaling and responses in plants. Cell 167, 313-324. doi: 10.1016/j.cell.2016.08.029

Conflict of Interest Statement: The authors declare that the research was conducted in the absence of any commercial or financial relationships that could be construed as a potential conflict of interest.

Copyright $\odot 2018 \mathrm{Wu}$ and Urano. This is an open-access article distributed under the terms of the Creative Commons Attribution License (CC BY). The use, distribution or reproduction in other forums is permitted, provided the original author $(s)$ and the copyright owner(s) are credited and that the original publication in this journal is cited, in accordance with accepted academic practice. No use, distribution or reproduction is permitted which does not comply with these terms. 